\title{
Significance of psychosocial factors in cardiology: update 2018
}

\author{
Position paper of the German Cardiac Society
}

\author{
Christian Albus $^{1} \cdot$ Christiane Waller $^{2} \cdot$ Kurt Fritzsche $^{3} \cdot$ Hilka Gunold $^{4} \cdot$ Markus Haass $^{5} \cdot$ Bettina Hamann $^{6}$. \\ Ingrid Kindermann $^{7} \cdot$ Volker Köllner $^{8}$ - Boris Leithäuser ${ }^{9} \cdot$ Nikolaus Marx $^{10,11} \cdot$ Malte Meesmann $^{12}$. \\ Matthias Michal ${ }^{13}$. Joram Ronel ${ }^{14}$ - Martin Scherer ${ }^{15} \cdot$ Volker Schrader $^{16}$ • Bernhard Schwaab ${ }^{17}$. \\ Cora Stefanie Weber ${ }^{18}$. Christoph Herrmann-Lingen ${ }^{19}$
}

Received: 14 December 2018 / Accepted: 29 April 2019 / Published online: 10 May 2019

(c) Springer-Verlag GmbH Germany, part of Springer Nature 2019

\begin{abstract}
Background Psychosocial factors in cardiovascular diseases are increasingly acknowledged by patients, health care providers and payer organizations. Due to the rapidly increasing body of evidence, the German Cardiac Society has commissioned an update of its 2013 position paper on this topic. The German version was published in 2018 and the current manuscript is an extended translation of the original version.

Methods This position paper provides a synopsis of the state of knowledge regarding psychosocial factors in the most relevant cardiovascular diseases and gives recommendations with respect to their consideration in clinical practice.

Results Psychosocial factors such as low socioeconomic status, acute and chronic stress, depression, anxiety and low social support are associated with an unfavorable prognosis. Psychosocial problems and mental comorbidities should be assessed routinely to initiate targeted diagnostics and treatment. For all patients, treatment should consider age and gender differences as well as individual patient preferences. Multimodal treatment concepts should comprise education, physical exercise, motivational counseling and relaxation training or stress management. In cases of mental comorbidities, brief psychosocial interventions by primary care providers or cardiologists, regular psychotherapy and/or medications should be offered. While these interventions have positive effects on psychological symptoms, robust evidence for possible effects on cardiac outcomes is still lacking.

Conclusions For coronary heart disease, chronic heart failure, arterial hypertension, and some arrhythmias, there is robust evidence supporting the relevance of psychosocial factors, pointing to a need for considering them in cardiological care. However, there are still shortcomings in implementing psychosocial treatment, and prognostic effects of psychotherapy and psychotropic drugs remain uncertain. There is a need for enhanced provider education and more treatment trials.
\end{abstract}

This position paper was consented by the German College of Psychosomatic Medicine (DKPM), the German Society of Psychosomatic Medicine and Medical Psychotherapy (DGPM), and the German Society on the Prevention and Rehabilitation of Cardiovascular Diseases (DGPR). The German version of the position paper was published previously as Albus $C$, Waller C, Fritzsche K, Gunold H, Haass M, Hamann B, Kindermann I, Köllner V, Leithäuser B, Marx N, Meesmann M, Michal M, Ronel J, Scherer M, Schrader V, Schwaab B, Weber CS, Herrmann-Lingen C. Bedeutung von psychosozialen Faktoren in der Kardiologie-update 2018. Positionspapier der Deutschen Gesellschaft für Kardiologie. Der Kardiologe 2018;12:312-31. The current manuscript is an extended translation of the original version.

Extended author information available on the last page of the article 
Keywords Cardiology · Psychosocial risk factors · Patient care · Psychotherapy · Psychopharmacology

\section{Preamble}

This position paper is an updated version of the 2013 publication, „Position paper on the importance of psychosocial factors in cardiology", by the German Cardiac Society (Deutsche Gesellschaft für Kardiologie, DGK [94]). In 2017, the DGK Committee on Clinical Cardiovascular Medicine approved a comprehensive revision due to significant developments, growing scientific evidence and an increase in acceptance of psychosocial factors in cardiology.

The position paper provides the current state of knowledge and aims to guide physicians, psychotherapists and their patients in making decisions regarding reasonable diagnostic and therapeutic measures.

\section{Introduction and methods}

Psychosocial factors such as low socioeconomic status, acute or chronic stress and depression or anxiety are highly prevalent in cardiac patients and are linked to behavioral and biological risk factors. Thus, they are related to a higher risk of cardiovascular disease and to an unfavorable course of illness. Due to available evidence as well as societal relevance, not only patients, care providers (cardiologists, general practitioners) and benefactors become more aware of these factors, but national and international guidelines and position papers have also increasingly taken such factors into account $[18,20,22,136,138]$. Table 1 summarizes the key arguments regarding the relevance of psychosocial factors in clinical care.

Our aim is not to provide a systematic review or strictly evidence-based guideline, but we rather summarize our expert opinion based on clinical experience and a focused literature review on psychosocial aspects for the most important cardiac diseases.

Table 1 Key arguments regarding the relevance of psychosocial factors in clinical practice

Psychosocial risk factors are

Highly prevalent in cardiac patients

Linked to behavioral and biological risk factors

Associated with increased risk of mortality and morbidity

Associated with lower quality of life

Barriers to lifestyle change and medication adherence

\section{Psychosocial aspects in the onset and course of selected cardiovascular diseases}

\section{General aspects}

The onset and course of the most frequent cardiovascular diseases can be described well on the basis of a biopsychosocial model: cardiovascular diseases develop based on individual genetic makeup in interaction with interpersonal experiences during childhood and adolescence as well as various environmental stressors, within a certain socioeconomic and cultural milieu [5].

Here environmental and behavioral factors play a larger role than genetic risk factors: through a healthy lifestyle, persons with high genetic risk can reduce their individual risk to that of persons with low genetic risk [82]. The onset of cardiovascular diseases is closely tied to a certain lifestyle (smoking, poor diet, inactivity, preventable exposure to stress) and could be avoided by most people, when compared to the extent of the present-day pandemic [1].

\section{Age}

While chronological age is a risk factor for myocardial infarction, the actual risk is substantially determined by modifiable risk factors [39]. Accordingly, the risk factor profile of a young heart attack patient differs clearly from that of an older patient: while younger heart attack patients are in fact more often male with a more frequent familial genetic predisposition, they are above all more frequently smokers [155]. In the INTERHEART study, psychosocial risk factors such as depression, critical life events, stress symptoms and financial problems accounted for $43.5 \%$ of the population attributable risk in younger patients (proportion of the population in whom myocardial infarction could be prevented if the risk factor could be completely eliminated), compared to $25.2 \%$ in older patients [188].

Frailty, social isolation and cognitive impairment become more important in advanced age, for example, for older patients with chronic heart failure who often later require palliative care [138]. Starting at 50 years of age, the prevalence of atrial fibrillation continuously increases with age [86]. In contrast, genetically conditioned and often life-threatening cardiac arrhythmias become manifest before age of 40 , which means that handling the heredity of such a disease is an important aspect of psychosocial care [13]. 


\section{Gender}

The available evidence supports a differentiation of gender-specific aspects with regard to the aetiopathogenesis and prognosis of cardiovascular diseases [18, 128, 141, 172].

In males, coronary heart disease (CHD) prevalence is consistently higher and increases exponentially starting at age 45 [62]. In females, the prevalence increases on average at age 55, but for females with low social status at age 45 [62]. For myocardial infarction, females are approximately 10 years older, present acutely with longer time latency, more frequently with atypical symptoms, have more comorbidities and receive less often optimal guideline-based therapy. Accordingly, post-infarction mortality is higher [2], especially in younger females [110].

In addition to older age, women have a higher prevalence of depression and posttraumatic stress disorder (PTSD), which in turn is associated with higher cardiovascular risk [173]. Early stress experiences in socially disadvantaged women as well as increased familial and professional demands in terms of gender-specific role conventions likely contribute as well [118]. Moreover, studies suggest higher stress vulnerability and exposure to stress in women, which are associated with atypical cardiovascular pathologies such as microvascular dysfunction or vasospasm [172]. Noteworthy also is the fact that approximately $90 \%$ of patients with Takotsubo cardiomyopathy are postmenopausal women. Further, gender-specific aspects are found in congestive heart failure (CHF), which manifests more frequently as tiredness and exhaustion in women [142] and in turn can be misinterpreted as depression. Arrhythmias, such as paroxysmal supraventricular tachycardia (SVT), are more often misinterpreted in women as panic attacks or other psychogenic symptoms, which results in delayed treatment (as with acute coronary syndrome) [25].

\section{Socioeconomic status}

Socioeconomic status is a significant predictor of cardiovascular morbidity and mortality [79, 165]. Indicators of social status are education, income, profession and place of residence. In high-income populations, it is especially persons with lower social status who are affected by cardiovascular diseases [163]. Constant lower social status across one's lifespan is associated with a twofold increased cardiovascular mortality [163].

Low social status is characterized by a cluster of workrelated factors (either no or precarious work contracts, unqualified work), environmental factors (low-grade housing, high crime rates, traffic noise, pollution) and high mental stress [118, 130].

\section{Social support}

Objective or subjective lack of social support is associated with a higher risk of developing cardiovascular diseases and a higher risk of mortality [174]. Lack of social support and loneliness are significant factors in single men for overall and cardiovascular mortality [162]. The effect of loneliness on mortality is comparable to that of heavy smoking (15 cigarettes per day; [187]).

\section{Importance of early stress experience}

Experiencing stress in early childhood such as violence, neglect, sexual and emotional abuse as well as social discrimination increases the risk for developing mental, cardiovascular and metabolic illnesses and as a result leads to increased mortality [72, 164]. Longitudinal studies show an inverse relationship between psychosocial well-being in childhood and adolescence and the incidence of atherosclerosis in adulthood [77].

\section{Biopsychosocial mechanisms}

Psychosocial factors such as low socioeconomic status, chronic stress or mental comorbidity are associated with an increased risk of cardiovascular morbidity and mortality [5]. Patients with severe mental disorders have a reduction of life expectancy by 10 years on average [55, 179]. A summary of psychosocial risk factors in selected cardiovascular diseases is given in Table 2. Important to note is that several of these factors are also negatively influenced by the experience of suffering from a cardiovascular disease itself.

The association between psychosocial factors and cardiovascular illnesses is mediated by behavioral and psychobiological mechanisms [5]. It is important to note that the respective factors and mechanisms interact with one another in a complex manner that is to some extent not yet fully understood.

Human behavior is based predominantly on environmental experiences even though genetic disposition also plays a role [46]. The social environment is of crucial importance for acquiring health-related knowledge, attitudes and behavioral patterns (health literacy) [158]. For example, low health literacy is particularly common for persons with lower socioeconomic status, which is in turn associated with disease-promoting behavior (e.g., smoking, poor diet, physical inactivity, medical non-adherence) [186].

Another important factor is the individual ability to adjust to mental and health-related demands. This comprises the ability to cope emotionally with diseases including adapting and/or maintaining favorable health-related behavior. 
Table 2 Established psychosocial risk factors in selected cardiac diseases

\begin{tabular}{ll}
\hline Disease & Risk factor \\
\hline Coronary heart disease & Acute and chronic stress \\
& Low socioeconomic status \\
& Low social support \\
& Depression; vital exhaustion \\
& Anxiety \\
& Posttraumatic stress disorder \\
& Type D personality, hostility \\
& Depression \\
Congestive heart disease & Anxiety \\
& Cognitive impairment \\
& Acute stress \\
Cardiac arrhythmias & Depression \\
& Anxiety \\
& Type D personality \\
& Posttraumatic stress disorder \\
Arterial hypertension & Social isolation \\
& Chronic stress \\
Takotsubo cardiomyopathy & Acute stress \\
& Comorbid depression \\
Somatoform and functional disorders & Comorbid anxiety \\
Adults with congenital heart disease & Acute stress \\
& Chronic stress \\
& Comorbid depression \\
& Comorbid anxiety \\
\hline
\end{tabular}

Despite high demands, several individuals are able to adequately adjust (high resilience), while others develop maladaptive, disease-promoting behavioral patterns.

For example, people with traumatic childhood experiences, chronic stress or mental comorbidities (e.g., depression, anxiety) exhibit more disease-promoting behavior [121]. The same holds for people with certain personality characteristics like the "Type D personality" [37] or chronic hostility [28].

In addition, dysfunctional activation of the neuroendocrine and stress axes have been described, which can result in reduced heart rate variability, increased inflammatory markers and activated coagulation [105, 180, 185]. Moreover, findings from animal experiments suggest additional epigenetic factors after biographical traumatization, but this must be confirmed by human studies [50]. Table 3 summarizes the main biological mechanisms related to psychosocial risk factors in selected cardiovascular diseases.

\section{Quality of life}

For chronic illnesses, for which symptom treatment is the central focus, health-related quality of life $(\mathrm{QoL})$ is especially important and is significantly influenced by mental factors $[101,153]$. QoL includes physical, social and mental dimensions of well-being and coping with everyday life. Patients with CHF show reduced health-related QoL, which is affected more by the existence of depressive symptoms than biomedical variables [153]. This also applies to patients with CHD [83]. Older age, female gender, a higher level of functional impairments, stronger comorbidity and hospitalization due to illness were predictors for lower QoL in patients with CHF [30]. For healthy individuals, psychological and physical QoL was an independent predictor of new onset of CHD and cerebrovascular events [17].

\section{Coronary heart disease}

\section{Psychosocial stress and CHD risk}

Chronic stress at the workplace can increase the risk for developing CHD [42, 134]. Moreover, shift work with night shifts or excessive overtime is associated with higher CHD risk [80].

Pronounced acute stress situations (e.g., anxiety, anger, grief) can lead to plaque ruptures via the acute response of stress hormones, the immune and the coagulation system, and thus trigger an acute myocardial infarction [124]. A large epidemiological study found that especially in the first $24 \mathrm{~h}$ after experiencing severe stress, such as the loss of a
Table 3 Main biological mechanisms related to psychosocial risk factors

\begin{tabular}{ll}
\hline Altered systems or mechanisms & Measures or symptoms \\
\hline Autonomic nervous system dysfunction & $\begin{array}{l}\text { Elevated plasma/urine catecholamines } \\
\text { Reduced vagal activity }\end{array}$ \\
& Reduced heart rate variability \\
& Elevated resting heart rate \\
& Reduced heart rate recovery \\
Hypothalamic-pituitary adrenal axis dysfunction & Flattened diurnal cortisol slope \\
& Altered cortisol awakening response \\
& Hyper-/hypocortisolism \\
Endothelial dysfunction & Reduced flow-mediated dilatation \\
Proinflammatory state & Elevated C-reactive protein \\
& Elevated interleukin-6 and tumor necrosis factor alpha \\
Prothrombotic state & Elevated fibrinogen, clotting factors, and fibrin D-dimer \\
& Increased platelet activity \\
\hline
\end{tabular}


loved one, the relative risk of a heart attack for the bereaved person is 21 times higher [122]. In contrast, social support or cohabitating with a spouse and family can serve as protective factors and reduce risk of illness and mortality after CHD manifestation [64].

\section{Mental disorders and CHD risk}

According to several meta-analyses, depressive disorders are associated with a higher risk for developing CHD (RR 1.6-1.9) as well as higher cardiovascular morbidity and mortality (OR 1.6-2.4) [32, 120]. Patients with schizophrenia die 10 years earlier from CHD than the normal population [183], and there is an increased cardiovascular risk for bipolar disorders [32]. A recent meta-analysis found for patients with the syndrome of "vital exhaustion" a relative risk of 1.5 for developing CHD and of 2.03 for re-infarction in patients with manifest CHD. The syndrome of "vital exhaustion" is characterized by symptoms such as fatigue and strong apathy, but lacks cognitive symptoms typical for depression (e.g., helplessness and hopelessness, self-incrimination) [51]. Depressive mood combined with exhaustion also yields an increased risk for cardiovascular mortality (RR 1.52; [92]). Acute, severe anxiety and anxiety disorders are associated with a higher risk for cardiovascular mortality (RR 1.4) and for CHD (RR 1.41) [44]. Phobic anxiety and panic disorders have the strongest link to an increased CHD risk [48]. Posttraumatic stress disorder (PTSD) is also associated with a higher risk of CHD [173].

\section{Mental comorbidities in clinically manifest CHD}

Depression following clinical manifestation of CHD and pronounced anxiety following myocardial infarction negatively influence survival and course of the disease [160]. A meta-analysis found that anxiety after a heart attack significantly predicts reoccurring myocardial infarction events and mortality (HR 1.38; [27]). In addition to several somatic comorbidities, depression is a meaningful factor for longterm impairments in patients following a heart attack [85].

PTSD symptoms occur in $12 \%$ of patients after myocardial infarction, but note that the prevalence strongly varies between 0 and 32\% [47]. The risk of mortality and/or reinfarction is doubled for post-infarction patients with PTSD symptoms compared to patients without PTSD symptoms (RR 2.0; [47]).

Patients that suffer from depressive symptoms before bypass surgery have a higher risk of death than patients without depression (HR 1.46; [159]). Pronounced depressive and anxiety symptoms following coronary bypass surgery significantly increase the 5-year risk for cardiovascular events (HR 3.79; [171]).

\section{Pathophysiological mechanisms}

As described in "General aspects", psychosocial risk factors negatively affect $\mathrm{CHD}$ via behavioral factors as well as direct biological mechanisms [105, 180, 185]. Stress and mental comorbidity promote the formation of plaques as well as their instability and rupture, but the exact mechanisms have not yet been clarified $[23,180]$.

\section{Clinical manifestation and demands for medical care}

Psychosocial factors can significantly affect the clinical presentation of CHD as well as the utilization of medical care. Old age, female gender, low socioeconomic status as well as denial, avoidance and/or underestimation of the relevance of heart-related symptoms of an acute coronary syndrome (ACS) are linked to delayed medical care [93].

In contrast, mental comorbidities may also lead to increased use of medical care. It can be difficult thereby to differentiate between anxiety-related physical symptoms or the somatic syndrome occurring as part of a depressive disorder and an acute coronary syndrome [157].

\section{Special considerations for coronary interventions}

Macroscopically successful coronary interventions do not always show the expected clinical improvement, which is primarily attributable to functional impairments of coronary vasomotion and microvascular function [126]. Placebo research could show that coronary physiology can be modulated by verbal suggestions [148].

After an acute coronary syndrome (ACS) or emergency percutaneous coronary intervention (PCI), acute stress reactions occur in approximately $13 \%$ of patients [147], and $4 \%$ develop a PTSD [37]. While an acute stress reaction subsides within the first 24-48 $\mathrm{h}$ after an ACS, PTSD develops up to 6 months later.

Up to a third of coronary bypass patients develop delirious symptoms [61]. Psychosocial factors such as old age, preexisting cognitive impairments and preexisting mental disorders are linked to a higher risk for delirium [61].

\section{Congestive heart failure}

\section{Mental comorbidity}

The prevalence of depressive disorders is $2-4$ times higher for congestive heart failure (CHF) patients than in the normal population [59]. Independent of "classical" prognostic predictors such as the left ventricular ejection fraction (LVEF) or N-terminal pro brain-derived natriuretic peptide (NTproBNP), depressive symptoms significantly increase overall mortality and cardiac mortality risk [56]. Anxiety 
symptoms occur frequently in people with CHF (ca. 30\%), however, they do not seem to have a clear prognostic relevance [178].

Depression and anxiety disorders can be easily overlooked, because symptoms such as difficulties in concentrating, fatigue, lethargy, loss of appetite and sleeplessness can also be due to CHF. Heart failure patients frequently suffer from a considerable reduction in QoL [20, 138]. With increasing clinical severity of CHF, the incidence of depression increases and self-reported physical as well as psychological QoL decreases [152].

Patients with CHF often show reduced adherence regarding necessary lifestyle changes and medication [138]. Lack of adherence is an important cause for cardiac decompensation, recurrent hospitalization, frequent doctor visits and loss in productivity at work [31]. Mental disorders such as anxiety, depression and cognitive impairment reduce adherence and the ability to quickly perceive changes in health status and take action accordingly [20]. Up to 50\% of CHF patients suffer from at least slight cognitive impairments, which are related to low cerebral perfusion resultant fromamong other things—generalized arteriosclerosis, as well as a reduced cardiac output and inflammatory processes [67].

\section{Heart transplantation and ventricular assist devices}

A thorough evaluation of psychosocial stressors or symptoms is necessary before heart transplantation or ventricular assist device (VAD) implantation [26]. Mental disorders such as depression or anxiety disorders should be identified and treated beforehand [26]. The implantation itself imposes a severe psychological burden on both the patients and their families. Even though most patients report better QoL, permanent dependence on a VAD, fear of organ rejection or the feeling of a foreign organ in one's own body, which is possibly even associated with feelings of guilt, are very burdensome for patients [156]. Family members are granted great importance and can play a major role in the patients' prognosis [14].

Despite possible burdens, the implantation of a VAD can improve the health-related QoL of both the patient and family members. This seems to be independent of the type of VAD system used (pulsatile or non-pulsatile) [26]. However, results on QoL and mental comorbidity are substantially worse for patients with VADs than for heart transplant patients [90]. Especially for younger patients, decreased adherence despite high QoL plays a meaningful role and should be improved using specific support programs [19]. Unlike nicotine abuse, preexisting addiction, anxiety, depression or non-adherence do not seem to be linked to higher 1-year mortality after VAD implantation [109]. Depression and anxiety, however, lead to higher re-hospitalization rates [109].

\section{Cardiac arrhythmias}

Strong negative as well as positive emotions can trigger arrhythmias, which in turn lead to mental stress [96]. The basis for the interdependency between emotions and cardiac electrophysiology is the interaction between long-term, stabile individual predisposing traits such as depressiveness, tendency towards anger and hostility (psychological substrate) and temporary, short-term psychosocial stimuli (psychological triggers; [133]).

Paroxysmal supraventricular tachycardia (SVT) sometimes causes severe anxiety states that can be mistaken for panic attacks. This is because they are often not documented in the electrocardiogram due to their short duration and spontaneous termination. Possible psychological triggers of SVTs have not yet been sufficiently examined [54].

The influence of psychosocial factors on the development and course of atrial fibrillation (AF) is still insufficiently researched. Acute triggers such as anxiety, despair or anger have been identified as predictors for new symptomatic AF [97]. Regarding predictors for recurrent AF, only one small prospective study exists, which found-in addition to various somatic factors-depressiveness, but not anxiousness or the combination of negative affect and social inhibition ("Type D personality"), to be predictive [98].

According to prospective cohort studies, psychological factors such as depressiveness, anxiety and the Type D personality significantly increase the vulnerability for ventricular tachyarrhythmia (VT) in heart patients [96]. Pronounced, acute stress can, however, elicit a VT, irrespective of acute ischemia or structural myocardial alterations [96]. The same applies for other acute major stressors such as terrorist attacks and earthquakes [96].

An implantable cardioverter defibrillator (ICD) implantation is very demanding on heart patients' ability to adjust mentally, which is reinforced by insufficient social support from family members, limited mobility (driving license) or sexual activity [75]. Approximately, one-fifth of patients suffer from symptoms such as anxiety and depression that is shock associated or that may occur as a result from traumatically experienced medical interventions [111]. These symptoms in turn are relevant predictors for adequate ICD shocks and mortality [175]. PTSD symptoms in ICD patients are associated with an unfavorable course of illness and higher mortality [91]. Moreover, there is evidence that problems in coping with illness can to some extent first appear with considerable delay and present as persisting symptoms of anxiety and depression and/or an ongoing increased vigilance towards the device [75]. 


\section{Arterial hypertension}

Psychosocial factors such as loneliness, sleep disorders and especially stress at work can contribute to the development of arterial hypertension [33]. For instance, $10 \mathrm{~h}$ of overtime work per week increases the incidence of hypertension by 3.2 times per year [33]. For patients that objectively suffer from insomnia, the risk of developing arterial hypertension is increased by more than 3 times [12]. However, data on the relationship between anxiety and the development of arterial hypertension are inconsistent [29]. From a clinical perspective, hypertension and its symptoms like, e.g., headaches and impaired vision can play a role in terms of the vicious cycle of anxiety in anxiety and panic disorders. Depression is currently being discussed as an independent risk factor for arterial hypertension [73].

From a psychobiological perspective, the activation of the renin-angiotensin system, especially the neuromodulator angiotensin II, does not only lead to high blood pressure, but also elicits worsening of mood and anxiety through oxidative stress in the central nervous system mediated via the nicotinamide adenine dinucleotide phosphate (NADPH) oxidase [107]. At the same time, there are findings that increased blood pressure can lead to emotional ease via baroreceptor stimulation $[65,66]$.

The influence of high blood pressure on the development of cognitive impairment and/or dementia has also been documented [113]. While executive dysfunctions are detectable in approximately $30 \%$ of older persons, the prevalence in hypertensive patients is much higher (around 50\%). In patients with therapy-refractory arterial hypertension, clinically relevant depressive symptoms could be found for $21 \%$ of patients, and elevated anxiety for 17\% [102].

Several studies show that QoL can decline during antihypertensive therapy, especially at the beginning of therapy [169]. However, medical antihypertensive therapy can contribute to improvement of psychosocial factors, for example, cognition [113]. First findings indicate that cognitive function, QoL as well as anxiety and depressive symptoms can be improved by catheter-based renal sympathetic denervation [84, 102].

\section{Takotsubo cardiomyopathy}

According to a large registry study, a third of all Takotsubo (or stress) cardiomyopathy cases are triggered by mental factors, in which a "broken-heart-syndrome" as well as isolated cases of "happy-heart-syndrome" have been described [166]. In another third, physical triggers were solely named. However, in many cases, these physical triggers were severe physical diseases or interventions that obviously include emotional stress. Based on criteria of the Diagnostic and Statistical Manual of Mental Disorders, 4th revision (DSM-IV), a current or previous mental disorder could be diagnosed in $45 \%$ of the patients in that cohort [166]. Most frequent were mood $(23 \%)$ or anxiety disorders $(11 \%)$. Seventeen percent of patients were currently taking antidepressants (mostly selective serotonin reuptake inhibitors; SSRIs). An excessive catecholamine release, impaired neuronal reuptake of norepinephrine, the formation of free radicals as well as the distribution of sympathetic nerves in the left ventricle with resulting damage to the myocardium via cytotoxic effects or microcirculation disorders are assumed to be the pathomechanisms involved [57]. Thus, it is discussed whether norepinephrine reuptake inhibition by certain antidepressants possibly increases the risk of this disease [57].

The rate for acute in-hospital complications is similar to that of acute coronary syndromes, with a seemingly better prognosis for older patients and for those with a primarily emotional trigger than patients with a physical trigger or those without an identifiable trigger [161]. Although left ventricular pump function is usually restored within days or weeks, future cardiovascular events are to be expected for $10 \%$ of Takutsubo cardiomyopathy patients, including relapses for 5\% [58]. The risk of relapse is possibly higher for patients with a preexisting mental disorder [125].

Recently, an international expert group introduced a novel clinical score (InterTAK Diagnostic Score) to differentiate Takotsubo syndromes form acute coronary syndromes [57, 58] to reduce underdiagnosis and treatment.

\section{Adults with congenital heart disease}

Depending on the complexity of the heart disease, adults with congenital heart disease may require lifelong intensive medical care including repeated highly specialized cardiac surgery. Life expectancy is affected in particular by congestive heart failure and cardiac arrhythmias. Medical trauma, limited daily-life participation, and reduced life expectancy require enormous adaptability from patients and their families [24, 144]. In most studies, these burdens increase the risk of mental disorders [36, 89, 114]. A third of the patients have a mental disorder [89]. Every second patient desires psychosocial support, mostly to deal with stress and burdens caused by their heart disease [89]. Without systematic screening, psychosocial problems are mostly overlooked [182], which leads to negative consequences regarding QoL and prognosis [41]. This is why cooperation with psychosomatic/psychocardiological care is a quality indicator for centers treating adults with congenital heart disease [78].

\section{Functional and somatoform disorders}

The spectrum of cardiovascular functional and somatoform symptoms ranges from vegetative cardiac complaints in the context of stress or anxiety to the now obsolete term of 
"cardiac neurosis" and to somatoform autonomous dysfunctions of the cardiovascular system (ICD 10: F 45.30; [3]).

The typical clinical picture is characterized by high psychological strain combined with high expectations regarding rapid symptom relief, which in many cases leads to disappointment and devaluation, which in turn leads to inadequate utilization of the medical system [3,9].

According to current data, one in six patients presenting to German family physicians with nonspecific/functional complaints has cardiopulmonary complaints as their primary complain [8]. Note that the etiology of these complaints is, however, mostly complex and imprecise. Traditionally, developmental psychological deficits that make it difficult for patients to distinguish between affective and physical experiences are considered to cause the symptoms. More recent aetiopathogenetic models are based on interactions between psychosocial, biological, iatrogenic/medical system-related and sociocultural factors that can lead to neurobiological alterations $[3,9]$.

\section{Diagnosis and therapy of psychosocial factors and mental comorbidity}

\section{Person-centered communication and basic psychosomatic care}

Patient (or person)-centered communication is the basis for developing a successful, trusting and cooperative doctor-patient relationship. As shown in Table 4, person centeredness comprises seven components [119], which are important to consider for high-quality care. Empathetic and supportive communication is of special importance to patient centeredness. Table 5 displays four simple communicative techniques that have been proven useful to establish an effective person-centered communication [99].

A recent meta-analysis has shown that person-centered communication has positive effects on patient satisfaction, adherence, utilization of medical care as well as outcome, e.g., a better reduction in blood pressure and reduced sensation of pain [144]. Hence, person-centered communication is recommended for everyday practice and can be learned with the help of specific training [76, 99, 104].

On the basis of patient-centered communication, cardiologists should also acquire the qualification in basic psychosomatic care to be able to cope with challenging situations, for example, mental comorbidity. The goals of basic psychosomatic care are [52]:

- Identifying mental and psychosomatic disorders and problems, also for complex cardiac illnesses (diagnostic competence),

- Limited offers for counseling, for example, during rounds, in informed consent conversation, before hospital discharge, for support in disease management or lifestyle modification, in crises and for information and advice, also including partners and family members (communicative competence),

- Indication for and referral to outpatient or inpatient psychotherapy and/or indication for psychosomatic or psychiatric consultation (competence for differentiated indications).

First evidence for the efficacy of trainings in basic psychosomatic care is available $[16,53]$.

Table 4 Components of person centeredness in health care [119]

1. Explore the patient's subjective experience with the disease

2. Perceive the patient as a whole person in his/her everyday reality

3. Make medical decisions together ("shared decision making")

4. Develop preventive and healthy activities together (i.e., more physical exercise, healthy food choice)

5. Strengthen the doctor-patient relationship by empathetic and supportive communication

6. Consider the physician's and the patient's available time frame and limited resources to avoid unrealistic goals

7. Consider the physician's personality, especially how he or she regulates emotional response, and need for specific training

Table 5 Basis communicative techniques in person-centered communication [99]

\begin{tabular}{ll}
\hline Waiting & Leave a 1-3 s break after your own questions or important statements from the patient \\
Repeating & Repeat important sentences or key words in the patient's last statement \\
Reflecting & Name emotions and moods (e.g., anxiety, insecurity) stated by the patient \\
Summarizing & $\begin{array}{l}\text { Summarize important passages of the conversation to signal understanding and pre- } \\
\text { vent misunderstandings }\end{array}$ \\
\hline
\end{tabular}




\section{Screening for psychosocial risk factors and mental comorbidity}

The German national disease management guideline ("Nationale VersorgungsLeitlinie", NVL) for chronic CHD generally recommends the simultaneous assessment of psychological, social and somatic information during diagnosis. Overall, screening for depression is recommended for patients with various underlying cardiac diseases [18, 22, 136, 138]; for patients with increased cardiovascular risk, CHD or ICD shocks, additional screening for anxiety and posttraumatic symptoms is recommended. According to the guideline, further mental disorders relevant for prognosis, for instance, schizophrenia or bipolar disorder, should be recorded. Additionally, the presence of psychosocial risk factors such as low socioeconomic status, social isolation, stress at work or family life, should be assessed during the consultation or via psychometric questionnaires. Specific suitable self-report questionnaires and/or questions on psychosocial risk factors are named in the German guideline [22] and the ESC prevention guideline [136]. Even though the informative value of the screening questions recommended by the ESC guideline as part of medical history taking is partly uncertain due to low sensitivity for personality factors [176], a suspicious screening result should generally prompt an expert clinical assessment using diagnostic interviews, as screening measures have been shown to have high sensitivity but low specificity [22, 136]. Table 6 displays core questions recommended by the Sixth Joint Task Force of the European Society of Cardiology and Other Society on Cardiovascular Disease Prevention in Clinical Practice [136] and selected psychometric questionnaires suitable for routine screening of psychosocial risk factors and mental comorbidity.

Even though an immediate benefit from screening per se is not sufficiently proven [167], subsequent referral to effective treatments that lead to improvement of mental symptoms, stress management and QoL-and that possibly can lower barriers against preventative behavioral changes - seems reasonable. Providing structured feedback on the screening results may positively influence the health status in the medium term [108].

\section{Behavior modification and promotion of medication adherence}

The current guideline on cardiovascular disease prevention from the European Society for Cardiology [136] provides the following recommendations for reduction of risk behavior and development of health-promoting behavior:
- "Established cognitive-behavioral strategies (e.g., motivational interviewing) to facilitate lifestyle change are recommended" [136]

- "Involvement of multidisciplinary healthcare professionals (e.g., nurses, dietitians, psychologists) is recommended" [136]

- "In individuals at very high CVD risk, multimodal interventions integrating medical resources with education on healthy lifestyle, physical activity, stress management and counseling on psychosocial risk factors, are recommended" [136]

Furthermore, the following principles of effective communication for promoting health behavior are recommended ([136], Table 7):

Frustration arises when behavior modification programs are offered to patients without considering their motivation, for example, when all smokers in a rehabilitation center are automatically assigned to the smoking cessation group. Instead, a step-by-step approach is recommended, e.g., the current German S3 guideline on smoking cessation [10]: for patients who are primarily not yet motivated to change their behavior, "motivational interviewing" is suitable to develop motivation to change [106]. First, smokers who are willing to quit but who are not able to without support should be offered a short or telephonebased consultation. Only when a more intensive treatment is needed or desired should individual or group behavioral therapy in conjunction with medication be offered [10].

A good practical example for a short consultation on smoking cessation is the "5A-method" (Table 8):

Structured counseling for smokers should begin in the acute care clinic and continue after discharge [11, 146], for example, by offers for telephone counseling [10]. Interventions with a longer duration have been proven to be more effective. There is evidence for increasing the effect by supplementary use of nicotine replacement therapy, but not for additional administration of bupropion or vareniclin [146]. There is evidence that counseling is more effective when conducted by the treating physician and not by nurses [140].

The information provided in Sect. "General aspects" on person-centered communication provides the foundation to improve medication adherence [34, 189]. A trusting doctor-patient relationship can increase adherence by about $30 \%$ [81]. The consultation should be structured on the basis of "shared decision making" [34, 115, 123].

For patients with cognitive impairments, e.g., in the context of CHF, dosing aids are an effective method to support adherence and to reduce re-hospitalization rates and mortality $[34,100]$. 
Table 6 Core questions [136] and selected psychometric questionnaires suitable for routine screening of psychosocial risk factors and mental comorbidity

\begin{tabular}{|c|c|c|c|c|c|}
\hline \multirow[t]{2}{*}{ Risk factor } & \multirow[t]{2}{*}{ Core questions } & \multicolumn{4}{|l|}{ Questionnaires } \\
\hline & & Name & Cutoff & $\begin{array}{l}\text { Time to } \\
\text { administer } \\
(\min )\end{array}$ & $\begin{array}{l}\text { Time for staff } \\
\text { to score (min) }\end{array}$ \\
\hline Low SES & $\begin{array}{l}\text { What is your highest educational degree? } \\
\text { (not more than mandatory) } \\
\text { Are you a manual worker? }\end{array}$ & n.a. & n.a. & n.a. & n.a. \\
\hline Social isolation & $\begin{array}{l}\text { Are you living alone? } \\
\text { Do you lack a close confidant? } \\
\text { Have you lost an important relative or friend } \\
\text { over the last year? }\end{array}$ & ESSI (5 items) & Yes & 2 & 1 \\
\hline Work/family stress & $\begin{array}{l}\text { Do you lack control over how to meet the } \\
\text { demands at work? } \\
\text { Is your reward inappropriate for your effort? } \\
\text { Do you have serious problems with your } \\
\text { spouse? }\end{array}$ & $\begin{array}{l}\text { ERI ( } 23 \text { items) } \\
\text { JCQ (42 items) }\end{array}$ & $\begin{array}{l}\text { No } \\
\text { No }\end{array}$ & $\begin{array}{l}10 \\
15\end{array}$ & $\begin{array}{l}10 \\
10\end{array}$ \\
\hline Depression & $\begin{array}{l}\text { Do you feel down, depressed and hopeless? } \\
\text { Have you lost interest and pleasure in life? }\end{array}$ & $\begin{array}{l}\text { HADS-depression (7 items) } \\
\text { PHQ-2 (2 items) } \\
\text { PHQ-9 (9 items) }\end{array}$ & $\begin{array}{l}\text { Yes } \\
\text { Yes } \\
\text { Yes }\end{array}$ & $\begin{array}{l}3 \\
1 \\
3\end{array}$ & $\begin{array}{l}1 \\
1 \\
1\end{array}$ \\
\hline Anxiety & $\begin{array}{l}\text { Do you suddenly feel fear or panic? } \\
\text { Are you frequently unable to control wor- } \\
\text { rying? }\end{array}$ & $\begin{array}{l}\text { HADS- anxiety ( } 7 \text { items) } \\
\text { GAD-7 ( } 7 \text { items) }\end{array}$ & $\begin{array}{l}\text { Yes } \\
\text { Yes }\end{array}$ & $\begin{array}{l}3 \\
3\end{array}$ & $\begin{array}{l}1 \\
1\end{array}$ \\
\hline Posttraumatic stress disorder & $\begin{array}{l}\text { Have you been exposed to a traumatic event? } \\
\text { Do you suffer from nightmares or intrusive } \\
\text { thoughts? }\end{array}$ & IES-R (22 items) & Yes & 10 & 5 \\
\hline Anger/hostility & $\begin{array}{l}\text { Do you frequently feel angry over little } \\
\text { things? } \\
\text { Do you often feel annoyed about other } \\
\text { people's habits? }\end{array}$ & STAXI-(44 items) & Yes & 15 & 10 \\
\hline Type D personality & $\begin{array}{l}\text { In general, do you often feel anxious, irrita- } \\
\text { ble, or depressed? } \\
\text { Do you avoid sharing your thoughts and feel- } \\
\text { ings with other people? }\end{array}$ & DS-14 (14 items) & Yes & 5 & 5 \\
\hline Cognitive impairments & $\begin{array}{l}\text { Do you have the impression that your } \\
\text { memory or other mental abilities have } \\
\text { decreased? }\end{array}$ & MOCA (12 tasks) & Yes & 10 & 1 \\
\hline Other mental disorders & $\begin{array}{l}\text { Do you suffer from any other mental disor- } \\
\text { ders? (e.g., bipolar disorder, schizophrenia) }\end{array}$ & n.a. & n.a. & n.a. & n.a. \\
\hline
\end{tabular}

n.a. not applicable, SES socioeconomic status, ESSI Enriched Social Support Questionnaire, ERI Effort-Reward Imbalance Scale, JCQ Job Content Questionnaire, HADS Hospital Anxiety and Depression Scale, $P H Q$ Patient Health Questionnaire, STAI State Trait Anxiety Inventory, GAD Generalized Anxiety Assessment Scale, IES-R Impact of Event Scale-Revised, STAXI State Trait Anger Inventory, DS-14 Type D Scale 14 items, MOCA Montreal Cognitive Assessment

Table 7 Principles of effective communication to facilitate behavioral change [136]

Spend enough time with the individual to create a therapeutic relationship —even a few more minutes can make a difference Acknowledge the individual's personal view of his/her disease and contributing factors

Encourage expression of worries and anxieties, concerns and self-evaluation of motivation for behaviour change and chances of success Speak to the individual in his/her own language and be supportive of every improvement in lifestyle Ask questions to check that the individual has understood the advice and has any support he or she requires to follow it Acknowledge that changing lifelong habits can be difficult and that sustained gradual change is often more permanent than a rapid change Accept that individuals may need support for a long time and that repeated efforts to encourage and maintain lifestyle change may be necessary in many individuals

Make sure that all health professionals involved provide consistent information 
Table 8 The "Five As" for a smoking cessation strategy for routine practice [136]

\begin{tabular}{ll}
\hline A-ASK & Systematically inquire about smoking status at every opportunity \\
A-ADVISE & Unequivocally urge all smokers to quit \\
A-ASSESS & Determine the person's degree of addiction and readiness to quit \\
A-ASSIST & Agree on a smoking cessation strategy, including setting a quit \\
& date, behavioral counseling and pharmacological support \\
A-ARRANGE & Arrange a schedule of follow up
\end{tabular}

\section{Multimodal interventions}

Multimodal interventions include medication, education, sports and exercise-based therapies as well as psychosocial approaches (especially motivational support, stress management $[22,136])$. The goal is to improve somatic, mental and social health, especially regarding emotional coping with cardiac events (i.e., reducing depressiveness and anxiety), to comprehensively encourage healthy behavior (lifestyle, stress management) and to improve QoL [5, 136]. Multimodal interventions do not primarily treat mental comorbidity (e.g., depression or anxiety disorders); this is treated by psychotherapy, complex psychosomatic-psychotherapeutic treatment and/or medication [5, 136].

Current meta-analyses on multimodal interventions for CHD patients show that exercise-based interventions (with or without psychosocial interventions) significantly improve health-related QoL and reduce the risk of rehospitalization and cardiovascular mortality, compared to control conditions [6, 139].

An additional current meta-analysis investigated the influence of psychological interventions with or without exercise-based interventions on CHD patients [143]. Compared to the control group, there was a $21 \%$ reduction of cardiovascular mortality as well as a decrease in depressive, anxiety and stress symptoms. Supplementing with psychosocial elements, however, had no significant effect on overall mortality, revascularization or non-lethal infarctions. However, the authors criticize the moderate to low quality of the studies. Questions remain regarding specificity of the therapy elements and which patients benefit the most from which psychological interventions [143].

According to an older meta-analysis, structured education for disease coping reduces the risk for re-hospitalization by $34 \%$ in CHF patients [116]. Dependent on the individual disease state of the patient, exercise training has weak positive effects on depression, QoL and physical performance [15]. According to current reviews, the so-called "mind-body interventions" (e.g., Tai chi, yoga, meditation, etc.) have weak to moderate positive effects on subjective and objective parameters such as QoL, depressiveness, resilience, heart rate and brain natriuretic peptide (BNP) [60].

\section{Psychotherapy and collaborative care}

The goals of psychotherapeutic interventions include decreasing mental symptoms, promoting disease management and modifying psychosocial risk factors. At the same time, barriers towards lifestyle change and to some extent biological risk factors can also be reduced $[5,6,69]$.

Already in the acute phase after myocardial infarction, short-term therapies in the hospital can yield a positive effect [6]. Several studies on individual psychotherapy with 3-5 sessions and with the objective to convey a realistic understanding of the illness, to process heart-related and mental symptoms and to promote individual strategies of action, report significantly reduced depression and/or anxiety symptoms, more heart-related knowledge and reduced physical impairment [6]. A current study on highly burdened patients with ACS could show that even one focused talk on coping with ACS-related burdens has a significant effect on depressive symptoms [177].

In the post-acute phase after myocardial infarction, group psychotherapy with 20 sessions for outpatient women with the goal of coping with stress as well as disease management was found to be linked to an almost 70\% reduction of overall mortality after 7 years [131]. A replication of this concept showed a significant reduction by $41 \%$ for cardiovascular events for both women and men [63].

It is unclear whether, and if so which, psychotherapeutic interventions are helpful for CHD patients with mental comorbidity (especially depression, anxiety disorders). According to a meta-analysis, cognitive behavioral therapy is moderately effective with respect to depressive symptoms, but no study to date has shown an improvement of cardiac prognosis [151]. However, across all studies, a "number needed to treat" of 84 was shown for the reduction of overall mortality and non-fatal events [151]. Therefore, there is moderate evidence that anti-depressive psychotherapy can improve the prognosis for CHD patients.

Regarding other psychotherapy approaches, a German research group could recently show that, compared to a conventionally treated control group, depressive CHD patients with Type D personality tended to profit more than patients without Type D personality from a stepwise, combined 
cognitive behavioral and psychodynamic therapy, in terms of their depressive symptoms [68].

A particularly promising outpatient therapy approach for depressive comorbidity in CHD is the so-called "collaborative care" [71], which coordinates various established treatment approaches (i.e., supportive talks and, if necessary, psychotherapy and/or antidepressants) parallel to cardiology basic treatment. There exist several controlled studies that report significant positive effects on mental health and to some extent on cardiac prognosis [170]. Stepwise, tailored selection of therapy methods as well as orientation on the patient's treatment preferences are considered to be fundamental elements [71]. The so-called "care managers" take on a central role in coordinating care; they screen all patients for depressive symptoms, when needed provide continuous support and bring in a psychotherapist and/or psychiatrist if symptoms are pronounced and/or sustained [71].

While Internet-based psychotherapy methods are generally effective for depression [87], there is limited evidence for CHD patients regarding improvements in QoL and lifestyle [38].

With respect to arterial hypertension, interventions such as relaxation techniques or biofeedback can reduce increased blood pressure. According to a meta-analysis [40], effects are on average about $5 \mathrm{mmHg}$ systolic/diastolic, thus being comparable to medical monotherapy. The evidence base is however weak.

While patients with CHF and comorbid depression or anxiety disorders profit from psychotherapy in terms of reduced depressiveness and anxiety as well as better QoL, an effect on cardiac prognosis could not be shown so far [74].

For patients with cardiac arrhythmias, there are only relatively few studies available. According to a systematic review, cognitive behavioral therapy improves depression and anxiety- or trauma-associated symptoms in ICD patients [112]. For ICD patients with PTSD, trauma-specific interventions (e.g., eye movement desensitization and reprocessing, EMDR) do not seem to be connected to a higher risk of cardiac arrhythmias [135]. In controlled studies with small numbers of cases, meditative forms of yoga could reduce the number of arrhythmia episodes, anxiety and depressiveness, and increase quality of life for ICD patients and patients with paroxysmal AF $[95,168]$.

No meaningful data are available on the effectiveness of psychotherapeutic treatment regarding recurrence prevention for patients with Takotsubo cardiomyopathy. Subjectively, patients are faced with the task of avoiding stress situations in the future, which is difficult, especially in cases of preexisting mental comorbidity. Therefore, it follows that patients with sustained mental disorders and/or stress should primarily be recommended psychotherapeutic treatment for their mental disorder and/or encouragement for stress management.

\section{Psychotropic drugs}

For CHD patients, selective serotonin reuptake inhibitors (SSRIs) such as sertraline or citalopram are the first choice, whose effectiveness for severe ore recurrent depressive syndromes could be documented [21, 151]. However, there is no robust evidence for an improvement in prognosis [21, 151]. In two randomized controlled trials (RCTs), neither sertraline nor escitalopram proved to be better than placebo for depressed patients with congestive heart failure [7, 127].

Due to its least amount of drug interactions, sertraline is considered to be relatively safe, compared to escitalopram and citalopram [21]. The latter received a warning in 2011 due to dose-dependent effects on the QT interval, which increases the risk for Torsades-de-pointes-tachycardia [21]. Anticholinergic effects of paroxetine, the long half-life of fluoxetine as well as the interactive potential of fluvoxamine are unfavorable for patients with heart disease [21].

SSRIs increase, however, bleeding risk, especially in combination with antiplatelet therapy, following gastrointestinal bleeding and in the perioperative setting [149]. Second-choice antidepressants such as mirtazapine, venlafaxine, bupropion and agomelatin partly have adverse effects on cardiovascular risk factors such as increase in appetite under mirtazapine and increased blood pressure under venlafaxine and bupropion [21]. Agomelatin has a favorable cardiac side-effect profile, if liver values are under control. Tricyclics should be avoided due to their quinidine-like adrenolytic and anticholinergic effects [21]. Hypericum (St. John's Wort) interacts with multiple somatic medications [21].

\section{Implementation of psychocardiological care}

\section{Primary care}

In light of shorter hospital stays and the increase in agerelated illnesses, multimorbidity and mental (co-)morbidities, primary care is becoming more important [35]. The task of a primary care physician is to provide long-term and comprehensive care, e.g., for chronically ill patients and, if necessary, to coordinate between different disciplines and/or professions. In the context of their long-term care, primary care physicians have the chance to identify and address psychosocial risks. Especially after onset of a heart disease, as a secondary preventative measure, primary care physicians can assess the necessity of psychosocial offers and provide concrete referrals. Here we advise close coordination with medical colleagues in the corresponding field (see "Outpatient cardiological care").

Therefore, in addition to classical risk factors, factors involving the personal environment, for example, acute or 
chronic stress at work or in the family should be assessed during medical history. It is also important to identify negative affect, especially anxiety or depressive mood, as well as social disadvantages or signs for a deficient social network. Appropriate screening measures are helpful for improving the problem of insufficient sensitivity during the diagnostic process (see "Screening for psychosocial risk factors and mental disorders").

The overall goal of doctor-patient communication in primary care is to decrease the high rate of unknown and/or untreated accompanying mental illnesses in patients with heart disease, and, ideally, to improve their prognosis. With the help of simple communication techniques, it is possible based on a long-term working alliancesome problem situations (see "Person-centered communication and basic psychosomatic care"). In cases of severe mental comorbidities, for example, major depression, personality disorders or pronounced addiction disorders, patients should be referred to specialized physicians or psychologists (see "Psychotherapy and collaborative care").

To improve the implementation of the aforementioned measures, continuing education offers and structured interdisciplinary networking are considered useful ("Diagnosis and therapy of psychosocial factors and mental comorbidity").

\section{Outpatient cardiological care}

Based on data from the EUROASPIRE IV study [88], the current risk factor control in CVD patients is inadequate. This holds for both primary care and outpatient cardiac care. According to expert's opinion, a comprehensive preventive approach should include assessment and treatment of psychosocial risk factors such as chronic stress, depressive symptoms, and anxiety [136, 137]. Unfortunately, lifestyle interventions in cardiologic outpatients are hampered by a lack of reimbursement and insufficient structures. The health insurance providers' Disease Management Program (DMP) for CHD includes lifestyle education, but is rarely offered by cardiologists. Referrals to heart exercise groups, psychiatric care or psychotherapy are common, but it remains unclear how many patients are adequately cared for.

From an expert's point of view, many factors contribute to the increased need for psychosocial care by cardiologists: old age, multimorbidity, limited competence in German, and social isolation in the old age [70]. At the same time, sector boundaries between inpatient and outpatient care and between medical specialties as well as too little available time for consultation with the individual patient hinder adequate care. Local or regional networks, for example, offering meetings for senior citizens are missing, and self-help groups are hardly available. The compensation for structured interviews or screening exists—if at all—only in some federal states and does not correspond to the required amount of time.

Although evidence is scarce for outpatients, cardiological care may be improved by a consistent implementation of guideline recommendations: simple questions on psychosocial risk factors asked during medical history taking $[22,136]$ or screening questionnaires, e.g., for depression or anxiety (see "Screening") are available. Data on QoL can also be collected with small investments of physicians' and patients' time [129, 150]. Recommendations for person-centered communication facilitate effective consultations and measures for encouraging adherence (verbal interventions; see "Person-centered communication" and "Behavior modification"). Relaxation techniques such as autogenic training, progressive muscle relaxation or mindfulness-based stress reduction are available for interested patient groups [103]. An outpatient liaison concept with psychotherapy is also possible in a cardiology practice and opens the possibility of low-threshold (group) psychotherapy. Consultations for couples can be integrated into consultation hours, and internet- and smartphone-based behavioral medicine approaches could be helpful regarding health-related behavior for interested CHD patients [132].

From an expert's point of view, however, a nationwide and adequate compensation for qualified screening and consultation, person-centered communication as well as patient education is a prerequisite for the implementation of psychocardiological care in cardiology practices. Furthermore, regulations regarding advanced training for psychosocial matters are desirable.

\section{Inpatient cardiological care}

On cardiological hospital wards, psychocardiological care is structurally problematic due to the short length of stay, but, according to expert's opinion, it is nonetheless useful.

Psychocardiological care in the context of an acute care hospital should pursue the following objectives:

- Identification of mental and psychosomatic disorders and problems also in patients with complex heart disease (diagnostic competence, see "Screening"),

- Time-limited consultation offers (communicative competence, see "Person-centered communication"),

- Indication for and referral to outpatient or inpatient specialist psychotherapy and/or indication for a psychosomatic consultation (competency in differential indication, see "Psychotherapy and collaborative care" and "Psychotropic drugs"),

- Classification of the relevance of individual patient risks at the interface to outpatient care (classifying competence, see "Psychotherapy and collaborative care" and "Psychotropic drugs"). 
Screening for mental comorbidity equivalent to that for somatic factors (see "Screening") should be offered, and the clinical relevance of the screening results should be examined. From an expert's point of view, competence in psychocardiology, comparable to that for psychooncology, is advisable.

Moreover, skills in basic psychosomatic care are advisable even for the cardiologist, because in clinical daily life worrying questions relating the illness are often asked, and inadequate perceptions of the illness need to be corrected. Short verbal interventions, such as correcting unrealistic fears have been shown to be effective [4]. Basic skills in psychosomatic care (see "Person-centered communication")—-here specifically framed as "psychocardiology"can be acquired through courses offered by the Academy of the German Society of Cardiology (http://www.akademie. dgk.org/default_home.aspx?navi=\&subnavi=).

Competence in psychocardiology is mandatory for personnel working in "Heart-Failure Units" and heart transplantation [20, 49]. To a greater extent, offers for psychosocial support should be established for patients before and after ICD implantation [18].

Psychosocial care before a coronary bypass can improve the clinical course of patients [145]. The complex burden of patients with congenital heart defects also requires psychosocial care [78].

Especially in older patients with long-lasting disease, terminal CHF and poor prognosis, the question arises as to which measures are ethically justifiable [181]. An optimized treatment plan should be individualized, involve patients and their close family members and follow the principles of shared decision making. In this context, a consensus should be reached regarding questions on whether and when pacemakers, ICDs and VADs should be deactivated, as well as regarding palliative care options [117].

Exemplary developments in recent years can be seen in psychocardiological wards, in which a coordinated overarching concept with simultaneous cardiology and psychosomatic treatment is used for patients with pronounced mental comorbidity. The complexity of the illnesses and treatments require high cardiologic and psychotherapeutic competence of the treatment teams as well as regular team meetings and supervision. Such offers remain therefore reserved for highly specialized institutions, but should be developed further given the high need.

\section{Cardiac rehabilitation}

Rehabilitation for patients with CVD is a multimodal intervention performed by an interdisciplinary team including somatic, psychological, educative and social aspects (see "Multimodal interventions"). Besides optimizing medical secondary prevention to reduce morbidity and mortality, rehabilitation also comprises improving physical abilities and QoL as well as reintegration into social and work life [154].

In 5 controlled cohort studies with 12,556 patients from Germany, it could be shown that rehabilitation after an acute myocardial infarction or coronary bypass surgery significantly reduced the re-infarction rate and hospitalizations over 1-2 years [154]. These national results were confirmed by an international meta-analysis for patients with coronary heart disease [6, 139]. Cardiac rehabilitation is recommended by national and international guidelines for patients after heart valve surgery and intervention, after decompensated heart failure, after heart transplantation as well as after ICD, cardiac re-synchronization therapy (CRT) and VAD implantation [184].

Pension insurance providers stipulate that the existence of comorbid mental disorders should be determined at the beginning of rehabilitation [43] (see "Screening"). Especially undetected cognitive impairments could jeopardize adherence and daily-life skills training. Psychoeducation should highlight factors influencing adequate coping, and explaining and destigmatizing mental disorders can make the utilization of professional help easier.

After the diagnoses of mental and neuropsychological problems and preventative psychoeducation, group interventions including relaxation training are indicated (see "Multimodal interventions"). These interventions should increase awareness for risk factors such as smoking or physical inactivity as well as help develop motivation for health-promoting behavioral changes [45] (see "Behavior modification"). From an expert's point of view, psychotherapy in a strict sense cannot be offered in cardiac rehabilitation. If there is a need for further psychological or neuropsychological treatment, the patient should be referred to an appropriate outpatient or inpatient facility (especially psychosomatic acute care hospitals or psychosomatic specialists, psychiatrists or psychological psychotherapists located near the patient's place of residence) while the patient is still in rehabilitation [45] (see "Psychotherapy and collaborative care" and "Psychotropic drugs").

For the care of psychologically distressed heart patients, concepts in line with behavioral medicine-oriented rehabilitation (BMR; In German "Verhaltensmedizinisch orientierte Rehabilitation") have been established, which take 4 instead of the usual 3 weeks [44]. An indication for BMR exists when a serious cardiac disease is the main illness that is accompanied by a meaningful mental component. If a mental disorder is the main illness, however, BMR is unsuitable. In this case, an indication for a psychosomatic-psychotherapeutic rehabilitation should be assessed [44].

To secure the sustainability of the rehabilitation success, rehabilitation aftercare programs are available. In addition, heart training groups have been established 
nationwide in Germany as long-term offers. They combine antidepressant effects of both physical exercise and social support und present therefore a valuable resource from a psychocardiological point of view.

\section{Summary of recommendations}

Especially for coronary heart disease (CHD), congestive heart failure (CHF), arterial hypertension and cardiac arrhythmias, there is convincing evidence regarding the significance of psychosocial factors with respect to screening and management in routine care. Table 9 displays a summary of core recommendations for treatment of psychosocial risk factors and mental comorbidity. In detail, we recommend the following:

\section{In general}

For all patients with cardiac diseases, the physician-patient interaction should follow the principles of person-centered communication. Age- and sex-specific aspects as well as individual preferences regarding diagnostics and therapy should be considered in accordance with principles of shared decision making $[22,136]$.

\section{CHD}

Psychosocial factors should be considered for all patients with cardiovascular risk factors or manifest CHD. Social factors (low social status, low social support) as well as psychological symptoms (depression, anxiety, posttraumatic stress disorder) should be assessed during the medical examination or with appropriate questionnaires. In case of positive screening, further specialized diagnostics and, if necessary, therapy should follow [2, 136].

All CHD patients should receive an individually tailored treatment plan which includes education, sports and exercise therapy, facilitation of life style change, relaxation techniques and stress management, if indicated [136].

In case of mental comorbidity, psychotherapeutic interventions and/or medications should be offered. If available, these interventions should be combined with basic psychosomatic care provided by the cardiologist or primary care physician. Collaborative care seems currently best suited to yield positive effects [136].

\section{CHF}

All patients with $\mathrm{CHF}$ should be screened for depression or an anxiety disorder. In case of positive screening, further specialized diagnostics and, if necessary, therapy should follow [138]. In case of comorbid depression, patients should be offered basic psychosomatic care. If this is not sufficient, psychotherapeutic treatment, especially cognitive behavioral
Table 9 Core recommendations for treatment of psychosocial risk factors and mental comorbidity

\begin{tabular}{ll}
\hline Risk factor & Treatment \\
\hline Low SES & Person-centered communication \\
& In case of cardiac events, cardiac rehabilitation \\
Social isolation & Person-centered communication \\
& Fostering of social networks, e.g., self-help groups \\
& In case of cardiac events, cardiac rehabilitation \\
Work/family stress & Person-centered communication and basic psychosomatic care \\
& Stress management training \\
& In case of cardiac events, cardiac rehabilitation \\
Depression & Person-centered communication and basic psychosomatic care \\
& Psychotherapy, antidepressants \\
& Collaborative care \\
& Heart groups \\
& In case of cardiac events, cardiac rehabilitation \\
& Person-centered communication and basic psychosomatic care \\
Anxiety & Psychotherapy, antidepressants \\
& Heart groups \\
& In case of cardiac events, cardiac rehabilitation \\
& Person-centered communication and basic psychosomatic care \\
Anger/hostility & Stress management training, psychotherapy \\
& In case of cardiac events, cardiac rehabilitation \\
Type D personality & Person-centered communication and basic psychosomatic care \\
& Stress management training \\
& In case of cardiac events, cardiac rehabilitation \\
\hline &
\end{tabular}


therapy and supplementary exercise training should be considered [138]. The involvement of a psychocardiological liaison service [49] is a mandatory feature of national heart failure centers, with offers for, among others, VAD recipients.

\section{Cardiac arrhythmias}

Particularly for paroxysmal atrial fibrillation, it is important to evaluate psychosocial stressors, because the use of relaxation techniques can relieve symptoms [95].

\section{ICD patients}

All patients should be screened for psychosocial stressors and mental comorbidity. Special attention has to be given to coping with ICD shocks. In case of mental comorbidity, psychotherapeutic treatment should be offered [18].

\section{Arterial hypertension}

If interested, patients should be offered relaxation techniques such as autogenic training, yoga and muscle relaxation [40].

\section{Takotsubo cardiomyopathy}

The acute treatment should avoid additional treatmentrelated stress exposure. Comorbid anxiety or mood disorders should be diagnosed during the acute situation and, if necessary, treated in accordance with relevant guidelines [58].

\section{Cardiac surgery}

Both patients with an indication for cardiac surgery and adults with congenital heart defects should be cared for by an interdisciplinary team which is able to address psychosocial aspects, provide general psychosocial support, and correct, e.g., dysfunctional expectations [145]. Psychosocial evaluation and, if necessary, co-treatment of all patients before and possibly after heart transplantation must occur in accordance with German transplantation laws.

\section{Somatoform and functional cardiovascular disorders}

Treatment should follow the principles of basic psychosomatic care and should primarily aim for a stabile physician-patient relationship. Iatrogenic chronification, which can be promoted by unnecessary-and especially repeatedinvasive diagnostics or prescription of cardiac medications, should be avoided. In case of inadequate effects of psychosomatic basic care on the symptoms, psychotherapeutic approaches and physical training should be recommended [9].

\section{Psychotropic medication}

Psychotropic drug therapy should only be given in case of mental comorbidity and under consideration of the underlying disease (e.g., questionable efficacy in patients with congestive heart failure, special caution in Takutsubo cardiomyopathy) and accompanying illnesses (for example, status post-ulcer bleeding, bleeding tendency under anticoagulation or antiplatelet therapy). Selective serotonin reuptake inhibitors (SSRIs) should be preferred. Tricyclic antidepressants should not be prescribed to patients with cardiovascular disease [21].

\section{Continuing education and training}

Psychocardiological issues should increasingly be included in continuing education and training programs. In particular, training in person-centered communication and basic psychosomatic care are suitable for improving the care of patients with psychosocial risk factors on a broad scale.

Acknowledgements The authors acknowledge Dr. Marlena Louise Litz for translating the original manuscript into medical English, which was funded by the Dept. of Psychosomatic Medicine at the University of Cologne.

Author contributions N. Marx has contributed to this position paper as a representative of the Committee on Clinical Cardiovascular Medicine of the German Cardiac Society.

\section{Compliance with ethical standards}

Conflict of interest The conflicts of interest of all authors are displayed online at the homepage of the German Cardiac Society (http:/leitlinien. org/), linked to the original German version of this article.

\section{References}

1. Aggarwal M, Devries S, Freeman A et al (2018) The deficit of nutrition education of physicians. Am J Med 131:339-345

2. Alabas OA, Gale CP, Hall $\mathrm{H}$ et al (2017) Sex differences in treatments, relative survival, and excess mortality following acute myocardial infarction: national cohort study using the SWEDEHEART Registry. J Am Heart Ass 6:e007123

3. Albus C, Herrmann-Lingen C (2009) Funktionelle Störungen in der Kardiologie. Herzmedizin 1:58-62

4. Albus C, Köhle K (2017) Krankheitsverarbeitung und psychotherapie nach Herzinfarkt. In: Köhle K, Herzog W, Joraschky P (eds) Psychosomatische medizin, 8th edn. Elsevier, München, pp 877-887

5. Albus C, Ladwig KH, Herrmann-Lingen C (2014) Psychocardiology: clinically relevant recommendations regarding selected cardiovascular diseases. Dtsch Med Wochenschr 139:596-601 
6. Anderson L, Thompson DR, Oldridge N et al (2016) Exercise-based cardiac rehabilitation for coronary heart disease. Cochrane Database Syst Rev 1:CD001800

7. Angermann CE, Gelbrich G, Störk S (2016) Effect of escitalopram on all-cause mortality and hospitalization in patients with heart failure and depression: the MOOD-HF randomized clinical trial. JAMA 315:2683-2693

8. Auhagen M (2017) Die Versorgungsrealität von Patienten mit nicht-spezifischen, funktionellen und somatoformen Körperbeschwerden in einer Hausarztpraxis im Ballungsraum München. In: Dissertation. Medizinischen Klinik und Poliklinik IV. LMU München, München

9. AWMF (Hrsg.) (2012) S3-Leitlinie "Umgang mit Patienten mit nicht-spezifischen, funktionellen und somatoformer Körperbeschwerden" AWMF-Register Nr. 051-001 (letzter Zugriff 09.01.2018)

10. AWMF (Hrsg.) (2014) S3-Leitlinie "Screening, Diagnostik und Behandlung des schädlichen und abhängigen Tabakkonsums" AWMF-Register Nr. 076-006 (letzter Zugriff 09.02.2018)

11. Balmford J, Leifert JA, Schulz C et al (2014) Implementation and effectiveness of a hospital smoking cessation service in Germany. Patient Educ Couns 94:103-109

12. Bathgate CJ, Edinger JD, Wyatt JK et al (2016) Objective but not subjective short sleep duration associated with Increased risk for hypertension in individuals with insomnia. Sleep 39:1037-1045

13. Beckmann BM, Pfeufer A, Kääb S (2011) Inherited cardiac arrhythmias: diagnosis, treatment and prevention. Dtsch Arztebl Int 108:623-634

14. Bidwell JT, Lyons KS, Mudd JO et al (2018) Patient and caregiver determinants of patient quality of life and caregiver strain in left ventricular assist device therapy. J Am Heart Assoc 7:e008080

15. Blumenthal JA, Babyak M, O'Connor C (2012) Effects of exercise training on depressive symptoms in patients with chronic heart failure: the HF-ACTION randomized trial. JAMA 308:465-474

16. Boissy A, Windover AK, Bokar D et al (2016) Communication skills training for physicians improves patient satisfaction. J Gen Intern Med 7:755-761

17. Bonaccio M, Di Castelnuovo A, Costanzo S et al (2018) Healthrelated quality of life and risk of composite coronary heart disease and cerebrovascular events in the Moli-sani study cohort. Eur J Prev Cardiol 25:287-297

18. Braunschweig F, Boriani G, Bauer A et al (2010) Management of patients receiving implantable cardiac defibrillator shocks: recommendations for acute and long-term patient management. Europace 12:1673-1690

19. Brocks Y, Zittermann A, Grisse D et al (2017) Adherence of heart transplant recipients to prescribed medication and recommended lifestyle habits. Prog Transplant 27:160-166

20. Bundesärztekammer (BÄK), Kassenärztliche Bundesvereinigung (KBV), Arbeitsgemeinschaft der Wissenschaftlichen Medizinischen Fachgesellschaften (AWMF) (2017) Nationale Versorgungsleitlinie Chronische Herzinsuffizienz-Langfassung, 2. Auflage. Version 2 (letzter Zugriff 3.2.2018)

21. Bundesärztekammer (BÄK), Kassenärztliche Bundesvereinigung (KBV), Arbeitsgemeinschaft der Wissenschaftlichen Medizinischen Fachgesellschaften (AWMF) (2015) Nationale VersorgungsLeitlinie Unipolare Depression-Langfassung (letzter Zugriff 3.2.2018)

22. Bundesärztekammer (BÄK), Kassenärztliche Bundesvereinigung (KBV), Arbeitsgemeinschaft der Wissenschaftlichen Medizinischen Fachgesellschaften (AWMF) (2016) Nationale VersorgungsLeitlinie Chronische KHK-Langfassung, 4. Auflage (letzter Zugriff 3.2.2018)
23. Burg MM, Edmondson D, Shimbo D et al (2013) The 'perfect storm' and acute coronary syndrome onset: do psychosocial factors play a role? Prog Cardiovasc Dis 55:601-610

24. Callus E, Quadri E (2014) Clinical psychology and congenital heart disease: lifelong psychological aspects and interventions. Springer, Milan

25. Carnlöf C, Iwarzon M, Jensen-Urstad M et al (2017) Women with PSVT are often misdiagnosed, referred later than men, and have more symptoms after ablation. Scand Cardiovas J 51:299-307

26. Caro MA, Rosenthal JL, Kendall K et al (2016) What the psychiatrist needs to know about ventricular assist devices: a comprehensive review. Psychosomatics 57:229-237

27. Celano CM, Millstein RA, Bedoya CA et al (2015) Association between anxiety and mortality in patients with coronary artery disease: a meta-analysis. Am Heart J 170:1105-1115

28. Chida Y, Steptoe A (2009) The association of anger and hostility with future coronary heart disease: a meta-analytic review of prospective evidence. J Am Coll Cardiol 53:936-946

29. Cohen BE, Edmondson D, Kronish IM (2015) State of the art review: depression, stress, anxiety and cardiovascular disease. Am J Hypertens 28:1295-1302

30. Comin-Colet J, Anguita M, Formiga F et al (2016) Healthrelated quality of life of patients with chronic systolic heart failure in Spain: results of the VIDA-IC study. Rev Esp Cardiol 69:256-271

31. Conraads V, Deaton C, Piotrowicz E (2012) Adherence of heart failure patients to exercise: barriers and possible solutions: a position statement of the Study Group on Exercise Training in Heart Failure of the Heart Failure Association of the European Society of Cardiology. Eur J Heart Fail 14:451-458

32. Correll CU, Solmi M, Veronese N et al (2017) Prevalence, incidence and mortality from cardiovascular disease in patients with pooled and specific severe mental illness: a large-scale metaanalysis of 3,211,768 patients and 113,383,368 controls. World Psychiatry 16:163-180

33. Cuffee Y, Odegegbe C, Williams NJ (2014) Psychosocial risk factors for hypertension: an update of the literature. Curr Hypertens Rep 16:483

34. Cutler DM, Everett W (2011) Thinking outside the pillboxmedication adherence as a priority for health care reform. New Engl J Med 362:1553-1555

35. DEGAM (2015) http://www.degam.de/files/Inhalte/Degam-Inhal te/Ueber_uns/Positionspapiere/DEGAM_Zukunftspositionen. pdf. Zugriff 26 Feb 2018

36. Deng LX, Khan AM, Drajpuch D et al (2016) Prevalence and correlates of post-traumatic stress disorder in adults with congenital heart disease. Am J Cardiol 117:853-857

37. Denollet J, Pedersen SS (2008) Prognostic value of Type D personality compared with depressive symptoms. Arch Int Med 168:431-432

38. Devi R, Singh SJ, Powell J et al (2015) Internet-based interventions for the secondary prevention of coronary heart disease. Cochrane Database Syst Rev 12:CD009386. https://doi. org/10.1002/14651858.cd009386.pub2

39. Dhingra R, Vasan RS (2012) Age as a cardiovascular risk factor. Med Clin N Am 96:87-91

40. Dickinson H, Campbell F, Beyer F et al (2008) Relaxation therapies for the management of primary hypertension in adults: a Cochrane review. J Hum Hypertens 22:809-820

41. Diller GP, Brautigam A, Kempny A et al (2016) Depression requiring anti-depressant drug therapy in adult congenital heart disease: prevalence, risk factors, and prognostic value. Eur Heart J 37:771-782

42. Dragano N, Siegrist J, Nyberg ST et al (2017) Effort-reward imbalance at work and incident coronary heart disease: a multicohort study of 90,164 individuals. Epidemiology 28:619-626 
43. DRV Bund (Hrsg.) (2011) Psychische Komorbidität. Leitfaden zur Implementierung eines psychodiagnostischen Stufenplans in der medizinischen. Rehabilitation

44. DRV Bund (Hrsg.) (2014) Strukturqualität von Reha-Einrichtungen-Anforderungen der Deutschen Rentenversicherung. 2. überarbeitete und erweiterte Auflage

45. DRV Bund (Hrsg.) (2017) Verhaltensmedizinisch orientierte Rehabilitation. Anforderungsprofil der Deutschen Rentenversicherung Bund für die verhaltensmedizinisch orientierte Rehabilitation (VOR)

46. Dunn SH, Conley YP (2015) A systematic review of genetic influences on coping. Biol Res Nurs 17:87-93

47. Edmondson D, Richardson S, Falzon L et al (2012) Posttraumatic stress disorder prevalence and risk of recurrence in acute coronary syndrome patients: a meta-analytic review. PLoS One 7:e38915

48. Emdin CA, Odutayo A, Wong CX et al (2016) Meta-analysis of anxiety as a risk factor for cardiovascular disease. Am J Cardiol 118:511-519

49. Ertl G, Angermann CE, Bekeredjian R et al (2016) Empfehlung Aufbau und Organisation von Herzinsuffizienz-Netzwerken (HF-NETs) und Herzinsuffizienz-Einheiten (,Heart Failure Units“, HFUs) zur Optimierung der Behandlung der akuten und chronischen Herzinsuffizienz. Kardiologe 10:222-235

50. Fiorito G, Polidoro S, Dugue PA et al (2017) Social adversity and epigenetic aging: a multi-cohort study on socioeconomic differences in peripheral blood DNA methylation. Sci Rep 7:16266

51. Frestad D, Prescott E (2017) Vital exhaustion and coronary heart disease risk: a systematic review and meta-analysis. Psychosom Med 79:260-272

52. Fritzsche K, Geigges W, Richter D et al (2015) Psychosomatische Grundversorgung. 2. Erweiterte Auflage. Springer, Heidelberg, pp 23-29

53. Fritzsche K, Schäfer I, Wirsching M et al (2012) Psychosomatische Grundversorgung im Krankenhaus-Eine empirische Untersuchung von biopsychosozialen Belastungen, Behandlungsmaßnahmen und Behandlungsergebnissen aus Sicht der Ärzte. Z Psychosom Med Psychother 58:142-157

54. Frommeyer G, Eckardt L, Breithardt G (2013) Panic attacks and supraventricular tachycardias: the chicken or the egg? Neth Heart J 21:74-77

55. Gale CR, Batty GD, Osborn DP et al (2014) Mental disorders across the adult life course and future coronary heart disease: evidence for general susceptibility. Circulation 129:186-193

56. Gathright EC, Goldstein CM, Josephson RA et al (2017) Depression increases the risk of mortality in patients with heart failure: a meta-analysis. J Psychosom Res 94:82-89

57. Ghadri JR, Wittstein IS, Prasad A et al (2018) International expert consensus document on Takotsubo syndrome (Part I): clinical characteristics, diagnostic criteria, and pathophysiology. Eur Heart J 39:2032-2046

58. Ghadri JR, Wittstein IS, Prasad A et al (2018) International expert consensus document on takotsubo syndrome (Part II): diagnostic workup, outcome, and management. Eur Heart J 39:2047-2062

59. Ghosh RK, Ball S, Prasad V (2016) Depression in heart failure: intricate relationship, pathophysiology and most updated evidence of interventions from recent clinical trials. Int J Cardiol 224:170-177

60. Gok Metin Z, Ejem D, Dionne-Odom JN (2018) Mind-body interventions for individuals with heart failure: a systematic review of randomized trials. J Card Fail 24:186-201

61. Gosselt AN, Slooter AJ, Boere PR et al (2015) Risk factors for delirium after on-pump cardiac surgery: a systematic review. Crit Care 19:346
62. Gößwald A, Schienkiewitz A, Nowossadeck E et al (2013) Prevalence of myocardial infarction and coronary heart disease in adults aged 40-79 years in Germany: results of the German Health Interview and Examination Survey for Adults (DEGS1). Bundesgesundheitsblatt Gesundheitsforschung Gesundheitsschutz 56:650-655

63. Gulliksson M, Burell G, Vessby B et al (2011) Randomized controlled trial of cognitive behavioral therapy vs standard treatment to prevent cardiovascular events in patients with coronary heart disease: secondary prevention in Uppsala primary health care project (SUPRIM). Arch Intern Med 171:134-140

64. Hagstrom E, Norlund F, Stebbins A et al (2018) Psychosocial stress and major cardiovascular events in patients with stable coronary heart disease. J Int Med 283:83-92

65. Hassoun L, Herrmann-Lingen C, Hapke U et al (2015) Association between chronic stress and blood pressure: findings from the German Health Interview and Examination Survey for Adults 2008-2011. Psychosom Med 77:575-582

66. Hassoun L, Meyer T, Busch MA et al (2016) Cardiovascular reactivity is independently associated with better mental health: results from the nationwide German DEGS1 study. Blood Press Monit 21:215-223

67. Havakuk O, Kings KS, Grazette L (2017) Heart failure-induced brain injury. J Am Coll Cardiol 69:1609-1616

68. Herrmann-Lingen C, Beutel ME, Bosbach A et al (2016) A stepwise psychotherapy intervention for reducing risk in coronary artery disease (SPIRR-CAD): results of an observer-blinded, multicenter, randomized trial in depressed patients with coronary artery disease. Psychosom Med 78:704-715

69. Herrmann-Lingen C, Köllner V, Boll-Klatt A (2014) Spezielle Verfahren und Techniken der Psychotherapie und Verhaltensmodifikation. In: Herrmann-Lingen C, Albus C, Titscher G (Hrsg.) Psychokardiologie. Ein Praxisleitfaden für Ärzte und Psychologen. Köln, Deutscher Ärzte-Verlag, 2. erweiterte und aktualisierte Aufl. 2014, pp 293-320

70. Holt-Lunstad J, Smith T, Layton J (2010) Social relationships and mortality risk: a meta-analytic review. PLoS Med 7:e100316

71. Huffman JC, Niazi SK, Rundell JR et al (2014) Essential articles on collaborative care models for the treatment of psychiatric disorders in medical settings: a publication by the Academy of Psychosomatic Medicine Research and Evidence-Based Practice Committee. Psychosomatics 55:109-122

72. Hughes K, Bellis MA, Hardcastle KA et al (2017) The effect of multiple adverse childhood experiences on health: a systematic review and meta-analysis. Lancet Public Health 8:e356-e366. https://doi.org/10.1016/S2468-2667(17)30118-4

73. Jackson CA, Pathirana T, Gardiner PA (2016) Depression, anxiety and risk of hypertension in mid-aged women: a prospective longitudinal study. J Hypertens 34:1959-1966

74. Jeyanantham K, Kotecha D, Thanki D (2017) Effects of cognitive behavioural therapy for depression in heart failure patients: a systematic review and meta-analysis. Heart Fail Rev 22:731-741

75. Jordan J, Sperzel J (2011) Psychokardiologischer praxisleitfaden fur die ICD-implantation und langzeitbetreuung. Herzschr Elektrophys 22:140-145

76. Jünger J, Köllner V, von Lengerke Th et al (2016) Kompetenzbasierter Lernzielkatalog » Ärztliche Gesprächsführung «. Z Psychosom Med Psychother 62:5-19

77. Juonala M, Pulkki-Raback L, Elovainio M et al (2016) Childhood psychosocial factors and coronary artery calcification in adulthood: the cardiovascular risk in young Finns study. JAMA Pediatr 170:466-472

78. Kaemmerer H, Breithardt G (2006) Empfehlungen zur Qualitätsverbesserung der interdisziplinären Versorgung von Erwachsenen mit angeborenen Herzfehlern (EMAH). Clin Res Cardiol 95:76-84 
79. Kamphuis CB, Turrell G, Giskes K et al (2012) Socioeconomic inequalities in cardiovascular mortality and the role of childhood socioeconomic conditions and adulthood risk factors: a prospective cohort study with 17-years of follow-up. BMC Public Health 12:1045

80. Kecklund G, Axelsson J (2016) Health consequences of shift work and insufficient sleep. BMJ 355:i5210

81. Kerse N, Buetow S, Mainous AG 3rd et al (2004) Physicianpatient relationship and medication compliance: a primary care investigation. Ann Fam Med 2:455-461

82. Khera AV, Emdin CA, Drake I et al (2016) Genetic risk, adherence to a healthy lifestyle, and coronary disease. N Engl J Med 375:2349-2358

83. Kim HS, Kim HK, Kang KO et al (2018) Determinants of health-related quality of life among outpatients with acute coronary artery disease after percutanoues coronary intervention. Jpn J Nurs Sci Mar. https://doi.org/10.1111/jjns.12209

84. Kindermann I, Wedegärtner SM, Mahfoud F (2017) Improvement in health-related quality of life after renal sympathetic denervation in real-world hypertensive patients: 12-month outcomes in the Global SYMPLICITY Registry. J Clin Hypertens 19:833-839

85. Kirchberger I, Heier M, Amann U et al (2016) Variables associated with disability in male and female long-term survivors from acute myocardial infarction. Results from the MONICA/ KORA Myocardial Infarction Registry. Prevent Med 88:13-19

86. Kirchhof P, Benussi S, Kotecha D et al (2016) 2016 ESC Guidelines for the management of atrial fibrillation developed in collaboration with EACTS. Eur Heart J 37:2893-2962

87. Königbauer J, Letsch J, Doebler P et al (2017) Internet- and mobile-based depression interventions for people with diagnosed depression: a systematic review and meta-analysis. J Affect Disord 223:28-40

88. Kotseva K, Wood D, De Bacquer D et al (2016) EUROASPIRE IV: a European Society of Cardiology survey on the lifestyle, risk factor and therapeutic management of coronary patients from 24 European countries. Eur J Prev Cardiol 23:636-648

89. Kovacs AH, Utens EM (2015) More than just the heart. Cardiol Clin 33:625-634

90. Kugler C, Malehsa D, Tegtbur U et al (2011) Health-related quality of life and exercise tolerance in recipients of heart transplants and left ventricular assist devices: a prospective, comparative study. J Heart Lung Transplant 30:204-210

91. Ladwig KH, Baumert J, Marten-Mittag B et al (2008) Posttraumatic stress symptoms and predicted mortality in patients with implantable cardioverter-defibrillators: results from the prospective living with an implanted cardioverter-defibrillator study. Arch Gen Psychiatry 65:1324-1330

92. Ladwig KH, Baumert J, Marten-Mittag B et al (2017) Room for depressed and exhausted mood as a risk predictor for allcause and cardiovascular mortality beyond the contribution of the classical somatic risk factors in men. Atherosclerosis 257:224-231

93. Ladwig KH, Fang X, Wolf $\mathrm{K}$ et al (2017) Comparison of delay times between symptom onset of an acute ST-elevation myocardial infarction and hospital arrival in men and women $<65$ years versus $>/=65$ years of age.: findings from the multicenter Munich examination of delay in patients experiencing acute myocardial infarction (MEDEA) Study. Am J Cardiol 120:2128-2134

94. Ladwig KH, Lederbogen F, Albus C et al (2013) Positionspapier zur Bedeutung von psychosozialen Faktoren in der Kardiologie. Update 2013. Kardiologe 2013:7-27

95. Lakkireddy D, Atkins D, Pillarisetti J et al (2013) Effect of yoga on arrhythmia burden, anxiety, depression, and quality of life in paroxysmal atrial fibrillation: the YOGA My Heart Study. J Am Coll Cardiol 61:1177-1182
96. Lampert R (2016) Behavioral influences on cardiac arrhythmias. Trends Cardiovasc Med 26:68-77

97. Lampert R, Jamner L, Burg M et al (2014) Triggering of symptomatic atrial fibrillation by negative emotion. J Am Coll Cardiol 64:1533-1534

98. Lange HW, Herrmann-Lingen C (2007) Depressive symptoms predict recurrence of atrial fibrillation after cardioversion. J Psychosom Res 63:509-513

99. Langewitz W (2017) Techniken der patientenzentrierten Kommunikation. In: Köhle (ed) Psychosomatische medizin-theoretische modelle und klinische Praxis, 8th edn. Elsevier, München, pp 293-298

100. Laufs U, Rettig-Ewen V, Böhm M (2011) Strategies to improve drug adherence. Eur Heart J 32:264-268

101. Lee KS, Lennie TA, Wu JR et al (2014) Depressive symptoms, health-related quality of life, and cardiac event-free survival in patients with heart failure: a mediation analysis. Qual Life Res 23:1869-1876

102. Lenski D, Kindermann I, Lenski M (2013) Anxiety, depression, quality of life and stress in patients with resistant hypertension before and after catheter-based renal sympathetic denervation. Eurointervention 9:700-708

103. Levine G, Lange A, Bairey-Merz N et al (2017) Meditation and cardiovascular risk reduction, a scientific statement from the American Heart Association. J Am Heart Assoc 6(10):e002218. https://doi.org/10.1161/aha.117.002218

104. Lewin SA, Skea ZC, Entwistle V et al (2001) Interventions for providers to promote a patient-centred approach in clinical consultations. Cochrane Database Syst Rev 4:CD003267

105. Lichtman JH, Froelicher ES, Blumenthal et al (2014) Depression as a risk factor for poor prognosis among patients with acute coronary syndrome: systematic review and recommendations: a scientific statement from the American Heart Asociation. Circulation 129:1350-1369

106. Lindson-Hawley N, Thompson TP, Begh R et al (2015) Motivational interviewing for smoking cessation. Cochrane Database Syst Rev 2:CD006936

107. Liu F, Havens J, Yu Q (2012) The link between angiotensin IImediated anxiety and mood disorders with NADPH oxidaseinduced oxidative stress. Int J Physiol Pathophysiol Pharmacol 4:28-35

108. Löwe B, Blankenberg S, Wegscheider K et al (2017) Depression screening with patient-targeted feedback in cardiology: DEPSCREEN-INFO randomised clinical trial. Br J Psychiatry 210:132-139

109. Lundgren S, Lowes BD, Zolty R et al (2017) Do psychosocial factors have any impact on outcomes after left ventricular assist device implantation? ASAIO J 64(4):e43-e47. https://doi. org/10.1097/MAT.0000000000000736

110. Ma QJ, Wang J, Jin J et al (2017) Clinical characteristics and prognosis of acute coronary syndrome in young women and men: a systematic review and meta-analysis of prospective studies. Int J Cardiol 228:837-843

111. Magyar-Russell G, Thombs BD, Cai JX et al (2011) The prevalence of anxiety and depression in adults with implantable cardioverter defibrillators: a systematic review. J Psychosom Res 71:223-231

112. Maia AC, Braga AA, Soares-Filho G et al (2014) Efficacy of cognitive behavioral therapy in reducing psychiatric symptoms in patients with implantable cardioverter defibrillator: an integrative review. Braz J Med Biol Res 47:265-272

113. Mancia G, Fagard R, Narkiewicz K (2013) 2013 ESH/ESC guidelines for the management of arterial hypertension: the Task Force for the management of arterial hypertension of the European Society of Hypertension (ESH) and of the European Society of Cardiology (ESC). Eur Heart J 34:2159-2219 
114. Marino BS, Lipkin PH, Newburger JW (2012) Neurodevelopmental outcomes in children with congenital heart disease: evaluation and management: a scientific statement from the American Heart Association. Circulation 126:1143-1172

115. Matthes J, Albus C (2014) Improving adherence with medication-a selective literature review based on the example of hypertension treatment. Dtsch Arztebl Int 111:41-47

116. McAlister F, Lawson F, Teo K et al (2001) A systematic review of randomized trials of disease management programs in heart failure. Am J Med 110:378-384

117. Mcilvennan CK, Jones J, Allen LA et al (2016) Bereaved caregiver perspectives on the end-of-life experience of patients with a left ventricular assist device. JAMA Intern Med 176:534-539

118. McSweeney JC, Rosenfeld AG, Abel WM et al (2016) Preventing and experiencing ischemic heart disease as a woman: state of the Science: a scientific statement from the American Heart Association. Circulation 133:1302-1331

119. Mead N, Bower P (2000) Patient-centredness: a conceptual framework and review of the empirical literature. Soc Sci Med $51: 1087$

120. Meijer A, Zuidersma M, De Jonge P (2013) Depression as a non-causal variable risk marker in coronary heart disease. BMC Med 11:130

121. Michal M, Subic-Wrana C, Beutel ME (2014) Psychodynamische psychotherapie, lebensstil und prävention. Z Psychosom Med Psychother 60(4):350-367

122. Mostofsky E, Maclure M, Sherwood JB et al (2012) Risk of acute myocardial infarction after the death of a significant person in one's life: the Determinants of Myocardial Infarction Onset Study. Circulation 125:491-496

123. Náfrádi L, Nakamoto K, Schulz PJ et al (2017) Is patient empowerment the key to promote adherence? A systematic review of the relationship between self-efficacy, health locus of control and medication adherence. PLoS One 12:e0186458

124. Nawrot TS, Perez L, Künzli N et al (2011) Public health importance of triggers of myocardial infarction: a comparative risk assessment. Lancet 377:732-740

125. Nayeri A, Rafla-Yuan E, Farber-Eger E et al (2017) Pre-existing psychiatric illness is associated with increased risk of recurrent takotsubo cardiomyopathy. Psychosomatics 58:527-532

126. Niccoli G, Montone RA, Lanza GA et al (2017) Angina after percutaneous coronary intervention: the need for precision medicine. Int J Cardiol 248:14-19

127. O'Connor CM, Jiang W, Kuchibhatla M et al (2010) Safety and efficacy of sertraline for depression on patients with heart failure. J Am Coll Cardiol 56:692-699

128. O'Neil A, Scovelle AJ, Milner AJ et al (2018) Gender/sex as a social determinant of cardiovascular risk. Circulation $137: 854-864$

129. Oldridge N, Höfer S, McGee H (2014) The Heart-QuoL: Part II. Validation of a new core health-related quality of life questionnaire for patients with ischemic heart disease. Eur J Prev Cardiol 21:98-106

130. Orth-Gomer K, Deter HC, Grün AS et al (2018) Socioeconomic factors in coronary artery disease-results from the SPIRR-CAD study. J Psychosom Res 105:125-131

131. Orth-Gomer K, Schneiderman N, Wang HX et al (2009) Stress reduction prolongs life in women with coronary disease. The Stockholm women's intervention trial for coronary heart disease (SWITCHD). Circ Cardiovasc Qual Outcomes 2:25-32

132. Palacios J, Lee GA, Duaso $M$ et al (2017) Internet-delivered self-management support for improving coronary heart disease and self-management-related outcomes; a systematic review. J Cardiovasc Nursing 32:E9-E23
133. Peacock J, Whang W (2013) Psychological distress and arrhythmia: risk prediction and potential modifiers. Prog Cardiovasc Dis 55:582-589

134. Pejtersen JH, Burr H, Hannerz H et al (2015) Update on workrelated psychosocial factors and the development of ischemic heart disease: a systematic review. Cardiol Rev 23:94-98

135. Peregrinova L, Jordan J (2017) Psychotherapy for posttraumatic stress disorders among cardiac patients after implantable cardioverter defibrillator shocks. Feasibility and implementation of a psychocardiological therapy manual in inpatient cardiac rehabilitation. Heart Mind 1:42-49

136. Piepoli MF, Hoes AW, Agewall S et al (2016) 2016 European Guidelines on cardiovascular disease prevention in clinical practice: the Sixth Joint Task Force of the European Society of Cardiology and Other Societies on Cardiovascular Disease Prevention in Clinical Practice (constituted by representatives of 10 societies and by invited experts). Developed with the special contribution of the European Association for Cardiovascular Prevention \& Rehabilitation (EACPR). Eur Heart J 37:2315-2381

137. Pogosova N, Kotseva K, De Bacquer D et al (2017) Psychosocial risk factors in relation to other cardiovascular risk factors in coronary heart disease: results from the EUROASPIRE IV survey. A registry from the European Society of Cardiology. Eur J Prev Cardiol 24:1371-1380

138. Ponikowski P, Voors AA, Anker SD et al (2016) 2016 ESC Guidelines for the diagnosis and treatment of acute and chronic heart failure. The Task force for the diagnosis and treatment of acute and chronic heart failure of the European Society of Cardiology (ESC). Developed with the special contribution of the Heart Failure Association (HFA) of the ESC. Eur J Heart Fail 37:2315-2381

139. Rauch B, Davos C, Doherty P et al (2016) The prognostic effect of cardiac rehabilitation in the era of acute revascularisation and statin therapy: a systematic review and meta-analysis of randomized and non-randomized - the Cardiac Rehabilitation Outcome Study (CROS). Eur J Prev Cardiol 23:1914-1939

140. Raupach T, Falk J, Vangeli E et al (2014) Structured smoking cessation training for health professionals on cardiology wards: a prospective study. Eur J Prev Cardiol 21:915-922

141. Regitz-Zagrosek V, Kararigas G (2017) Mechanistic pathways of sex differences in cardiovasular disease. Physiol Rev 97:1-37

142. Regitz-Zagrosek V, Oertelt-Prigione S, Seeland U et al (2010) Sex and gender differences in myocardial hypertrophy and heart failure. Circ J 74:1265-1273

143. Richards SH, Anderson L, Jenkinson CE et al (2017) Psychological interventions for coronary heart disease (review). Cochrane Database Syst Revi 4:CD002902

144. Riedl D, Schüßler G (2017) The Influence of doctor-patient communication on health outcomes: a systematic review. Z Psychosom Med Psychother 63:131-150

145. Rief M, Shedden-Mora MC, Laferton JAC et al (2017) Preoperative optimization of patient expectations improves long-term outcome in heart surgery patients: results of the randomized controlled PSY-HEART trial. BMC Med 15:4-17

146. Rigotti NA, Clair C, Munafò MR et al (2012) Interventions for smoking cessation in hospitalised patients. Cochrane Database Syst Rev 16(5):CD001837. https://doi.org/10.1002/14651858. cd001837.pub3

147. Roberge MA, Dupuis G, Marchand A (2008) Acute stress disorder after myocardial infarction: prevalence and associated factors. Psychosom Med 70:1028-1034

148. Ronel J, Mehilli J, Ladwig KH et al (2011) Effects of verbal suggestion on coronary arteries: results of a randomized controlled experimental investigation during coronary angiography. Am Heart J 162:507-511 
149. Roose SP, Rutherford BR (2016) Selective serotonin reuptake inhibitors and operative bleeding risk: a review of the literature. J Clin Psychopharmacol 36:704-709

150. Rumsfeld J, Alexander K, Goff D et al (2013) Cardiovascular health: the importance of measuring patient-reported health status. Circulation 127:2233-2249

151. Rutledge T, Redwine LS, Linke SE et al (2013) A meta-analysis of mental health treatments and cardiac rehabilitation for improving clinical outcomes and depression among patients with coronary heart disease. Psychosom Med 75:335-349

152. Rutledge T, Reis VA, Linke SE et al (2006) Depression in heart failure a meta-analytic review of prevalence, intervention effects, and associations with clinical outcomes. J Am Coll Cardiol 48:1527-1537

153. Schowalter MG, Gelbrich G, Störk S et al (2013) Generic and disease-specific health-related quality of life in patients with chronic systolic heart failure: impact of depression. Clin Res Cardiol 102:269-278

154. Schwaab B (2018) Kardiologische rehabilitation. Rehabilitation 57:17-26

155. Shah NA, Kelly AM, Cox N et al (2016) Myocardial infarction in the "young": risk factors, presentation, management and prognosis. Heart Lung Circ 25:955-960

156. Shemesh Y, Peles-Bortz A, Peled Y et al (2017) Feelings of indebtedness and guilt toward donor and immunosuppressive medication adherence among heart transplant (HTx) patients, as assessed in a cross-sectional study with the Basel Assessment of Adherence to Immunosuppressive Medications Scale (BAASIS). Clin Transplant. https://doi.org/10.1111/ctr.13053

157. Soares-Filho GL, Arias-Carrion O, Santulli G et al (2014) Chest pain, panic disorder and coronary artery disease: a systematic review. CNS Neurol Dis Drug Targets 13:992-1001

158. Sørensen K, Van den Broucke S, Fullam J et al (2012) Health literacy and public health: a systematic review and integration of definitions and models. BMC Public Health 12:80. https://doi. org/10.1186/1471-2458-12-80

159. Stenman M, Holzmann MJ, Sartipy U (2016) Association between preoperative depression and long-term survival following coronary artery bypass surgery-a systematic review and meta-analysis. Int J Cardiol 222:462-466

160. Stewart RH, Colquhoun DM, Marschner SL et al (2017) Persistent psychological distress and mortality in patients with stable coronary artery disease. Heart 103:1860-1866

161. Stiermaier T, Eitel C, Denef S et al (2015) Prevalence and clinical significance of life-threatening arrhythmias in Takotsubo cardiomyopathy. J Am Coll Cardiol 65:2148-2150

162. Stringhini S, Berkman L, Dugravot A et al (2012) Socioeconomic status, structural and functional measures of social support, and mortality: the British Whitehall II Cohort Study, 1985-2009. Am J Epidemiol 175:1275-1283

163. Stringhini S, Zaninotto P, Kumari M et al (2018) Socio-economic trajectories and cardiovascular disease mortality in older people: the English Longitudinal Study of Ageing. Int J Epidemiol 47:36-46

164. Suglia SF, Koenen KC, Boynton-Jarrett R et al (2018) Childhood and adolescent adversity and cardiometabolic outcomes: a scientific statement from the American Heart Association. Circulation 137:e15-e28

165. Tang KL, Rashid R, Godley J et al (2016) Association between subjective social status and cardiovascular disease and cardiovascular risk factors: a systematic review and meta-analysis. BMJ Open 6:e010137

166. Templin C, Ghadri JR, Diekmann J et al (2015) Clinical features and outcomes of Takotsubo (Stress) cardiomyopathy. N Engl J Med 373:929-938
167. Thombs BD, Roseman M, Coyne JC et al (2013) Does evidence support the American Heart Association's recommendation to screen patients for depression in cardiovascular care? An updated systematic review. PLoS One 8:e52654

168. Toise SC, Sears SF, Schoenfeld MH et al (2014) Psychosocial and cardiac outcomes of yoga for ICD patients: a randomized clinical control trial. Pacing Clin Electrophysiol 37:48-62

169. Trevisol DJ, Moreira LB, Fuchs FD et al (2012) Health-related quality of life is worse in individuals with hypertension under drug treatment: results of population-based study. J Hum Hypertens $26: 374-380$

170. Tully PJ, Baumeister H (2015) Collaborative care for comorbid depression and coronary heart disease: a systematic review and meta-analysis of randomised controlled trials. BMJ Open 5(12): 0009128

171. Tully PJ, Winefield HR, Baker RA et al (2015) Depression, anxiety and major adverse cardiovascular and cerebrovascular events in patients following coronary artery bypass graft surgery: a five year longitudinal cohort study. BioPsychoSoc Med 9:14

172. Vaccarino V, Bremner JD (2017) Behavioral, emotional and neurobiological determinants of coronary heart disease risk in women. Neurosci Biobehav Rev 74:297-309

173. Vaccarino V, Goldberg J, Rooks C et al (2013) Post-traumatic stress disorder and incidence of coronary heart disease: a twin study. J Am Coll Cardiol 62:970-978

174. Valtorta NK, Kanaan M, Gilbody S et al (2016) Loneliness and social isolation as risk factors for coronary heart disease and stroke: systematic review and meta-analysis of longitudinal observational studies. Heart 102:1009-1016

175. Van Den Broek KC, Tekle FB, Habibovic M et al (2013) Emotional distress, positive affect, and mortality in patients with an implantable cardioverter defibrillator. Int J Cardiol 165:327-332

176. van Montfort E, Denollet J, Widdershoven J et al (2017) Validity of the European Society of Cardiology's psychosocial screening interview in patients with coronary artery disease- the THORESCI Study. Psychosom Med 79:404-415

177. von Känel R, Barth J, Princip M et al (2018) Early psychological counseling for the prevention of posttraumatic stress induced by acute coronary syndrome: the MI-SPRINT randomized controlled trial. Psychother Psychosom 87:75-84

178. Vongmany J, Hickman LD, Lewis J (2017) Anxiety in chronic heart failure and the risk of increased hospitalisations and mortality: a systemic review. Eur J Cardiovasc Nurs 15:478-485

179. Wahlbeck KJ, Westman J, Nordentoft M et al (2011) Outcomes of Nordic mental health systems: life expectancy of patients with mental disorders. Br J Psychiatry 199:453-458

180. Waller C, Bauersachs J, Hoppmann U et al (2016) Blunted cortisol stress response and depression-induced hypocortisolism is related to inflammation in patients With CAD. J Am Coll Cardiol 67:1124-1126

181. Warraich HJ, Hernandez AF, Allen LA (2017) How medicine has changed the end of life for patients with cardiovascular disease. J Am Coll Cardiol 70:1276-1289

182. Westhoff-Bleck M, Briest J, Fraccarollo D et al (2016) Mental disorders in adults with congenital heart disease: unmet needs and impact on quality of life. J Affect Disord 204:180-186

183. Westman J, Eriksson SV, Gissler M et al (2017) Increased cardiovascular mortality in people with schizophrenia: a 24-year national register study. Epidemiol Psychiatric Sci 5:1-9

184. Willemsen D, Cordes C, Bjarnason-Wehrens B et al (2016) Rehabilitationsstandards für die Anschlussheilbehandlung und allgemeine Rehabilitation von Patienten mit einem Herzunterstützungssystem (VAD). Clin Res Cardiol Suppl 11(Suppl 1):2-49

185. Wirtz PH, Von Kanel R (2017) Psychological stress, inflammation, and coronary heart disease. Curr Cardiol Rep 19:111 
186. World Health Organization (2013) Health literacy. The solid facts. WHO regional office for Europe, Copenhagen

187. Xia N, Li H (2018) Loneliness, social isolation, and cardiovascular health. Antioxid Redox Signal 28:837-851

188. Yusuf SS, Hawken S, Ounpuu S et al (2004) Effect of potentially modifiable risk factors associated with myocardial infarction in
52 countries (the INTERHEART study): case-control study. Lancet 364:937-952

189. Zolnierek KB, Dimatteo MR (2009) Physician communication and patient adherence to treatment: a meta-analysis. Med Care $47: 826-834$

\section{Affiliations}

\section{Christian Albus $^{1} \cdot$ Christiane Waller $^{2} \cdot$ Kurt Fritzsche $^{3} \cdot$ Hilka Gunold $^{4} \cdot$ Markus Haass $^{5} \cdot$ Bettina Hamann $^{6}$. Ingrid Kindermann ${ }^{7} \cdot$ Volker Köllner $^{8} \cdot$ Boris Leithäuser $^{9} \cdot$ Nikolaus Marx $^{10,11} \cdot$ Malte Meesmann $^{12}$. Matthias Michal ${ }^{13}$. Joram Ronel ${ }^{14} \cdot$ Martin Scherer $^{15} \cdot$ Volker Schrader $^{16} \cdot$ Bernhard Schwaab $^{17}$. Cora Stefanie Weber ${ }^{18}$. Christoph Herrmann-Lingen ${ }^{19}$}

\section{Christian Albus}

christian.albus@uk-koeln.de

1 Department of Psychosomatic Medicine and Psychotherapy, University Hospital of Cologne, Kerpenerstr. 62, 50937 Cologne, Germany

2 Department of Psychosomatic Medicine and Psychotherapy, Paracelsus Medical University, Nuremberg General Hospital, Nuremberg, Germany

3 Department of Psychosomatic Medicine and Psychotherapy, University Medical Center Freiburg, Freiburg, Germany

4 Department of Cardiology, University Medical Center Leipzig, Leipzig, Germany

5 Department of Cardiology, Angiology and Intensive Care, Theresienkrankenhaus, Mannheim, Germany

6 Department of Psychocardiology, Kerckhoff-Klinik, Bad Nauheim, Germany

7 Department of Internal Medicine III (Cardiology, Angiology and Intensive Care), Saarland University Medical Center, Homburg/Saar, Germany

8 Department of Psychosomatics and Behavioural Medicine, Seehof Rehabilitation Center, Teltow, Germany

9 Preventive Care Center, Cardiovascular Practice, Hamburg, Germany
10 Department of Internal Medicine I, Cardiology, Angiology and Intensive Care, University Hospital Aachen, Aachen, Germany

11 For the Committee on Clinical Cardiovascular Medicine of the German Cardiac Society, Düsseldorf, Germany

12 Department of Cardiology, Juliusspital, Würzburg, Germany

13 Department of Psychosomatic Medicine and Psychotherapy, University Medical Center Mainz, Mainz, Germany

14 Department of Psychosomatic Medicine and Psychotherapy, Clinic Barmelweid, Erlinsbach, Switzerland

15 Institute and Clinic of General Practice and Primary Care, Medical Center Hamburg-Eppendorf, Hamburg, Germany

16 Cardiopulmonary Practice, Nuremberg, Germany

17 Curschmann Klinik, Timmendorfer Strand, Germany

18 Department of Psychosomatic Medicine and Psychotherapy, Hennigsdorf Hospital, Hennigsdorf, Germany

19 Department of Psychosomatic Medicine and Psychotherapy, University of Göttingen Medical Centre and German Centre for Cardiovascular Research (DZHK), partner site, Göttingen, Germany 